UNITED STATES DEPARTMENT OF THE INTERIOR GEOLOGICAL SURVEY

\title{
Noise Analysis of the Seismic System Employed in the Northern and Southern California Seismic Nets
}

\author{
by J. P. Eaton1
}

Open-File Report 84- 657

This report is preliminary and has not been reviewed for conformity with U.S. Geological Survey standards and stratigraphic nomenclature.

1. USGS Menlo Park, California 


\section{Introduction}

The seismic networks have been designed and operated to support recording on Develocorders (less than $40 \mathrm{db}$ dynamic range) and analog magnetic tape (about $50 \mathrm{db}$ dynamic range). The principal analysis of the records has been based on Develocorder films; and background earth noise levels have been adjusted to be about 1 to $2 \mathrm{~mm} p-p$ on the $\mathrm{f} 1 \mathrm{~mm}$ readers. Since the traces are separated by only 10 to $12 \mathrm{~mm}$ on the reader screen, they become hopelessly tangled when signal amplitudes on several adjacent traces exceed 10 to $20 \mathrm{~mm} \mathrm{p}-\mathrm{p}$. Thus, the background noise level is hardly more than $20 \mathrm{db}$ below the level of largest readable signals. The situation is somewhat better on tape playbacks, but the high level of background noise set to accomodate processing from film records effectively limits the range of maximum-signal to background-earth-noise on high gain channels to a little more than $30 \mathrm{db}$.

Introduction of the PDP $11 / 44$ sefsmic data acquisition system has increased the potential dynamic range of recorded network signals to more than $60 \mathrm{db}$. To make use of this increased dynamic range we must evaluate the characteristics and performance of the seismic system. In particular, we must determine whether the electronic noise in the system is or can be made sufficiently low so that background earth noise levels can be lowered significantly to take advantage of the increased dynamic range of the digital recording system.

To come to grips with the complex problem of system noise, we have carried out a number of measurements and experiments to evaluate critical components of the system as well as to determine the noise characteristics of the system as a whole. This report is composed of the following sections:

\section{Int roduction}

Overview of noise sources in various parts of the system Analysis of preamp noise versus combined modulator/discriminator noise Network-wide analysis of noise on Dec. 20, 1983 from magnetic tape playbacks

Analysis of noise on low-gain channels -Dec. 20, 1983

Analysis of system noise during the automatic calibration cycle (March $22,1984)$

Summary and conclusions

\section{Overview of noise sources}

Relative to the signals produced by earthquakes, there are two types of noise to consider:

1) the seismic ground noise, etc., that enters the system through the seismometer in the same manner as earthquakes, and 2) the electronic noise generated in the system itself. The level of background earth noise at the discriminator output should be sufficiently above the level of the electronic noise that the combined signal has the general character of the earth noise, not the electronic noise. This condition requires that the ground noise be about $12 \mathrm{db}$ above the electronic noise. Provided that the preamp noise, referred to the preamp input, is sufficiently smaller than the signal produced 
by the seismometer, the foregoing condition can be met by adjusting the field unit attenuator.

:

Our primary task is to analyze the electronic system noise in order to understand where it originates and how it can be controlled. In this analysis it is generally convenient to measure the strength of a noise source by the level of noise it produces at the discriminator output. The accompanying schematic diagram ( $f i g$ l) shows how the system is composed and indicates its principal sources of noise.

$\mathrm{Ng}$

A moving coil seismometer converts ground motion into a very low level low frequency signal that is communicated to the field preamp/vco unit through the seismometer cable. For a normally operating seismometer the noise signal, Ng, produced by the seismometer is due to normal background microseismic and cultural seismic noise. From the viewpoint of the seismic system, the ground noise is a perfectly valid signal that should not be treated as system noise.

Nsc

Occasional defects in the seismometer cable or in the electrical isolation of the seismometer from ground, or pick-up of other induced signals from locally strong, time varying radio frequency sources (nearby radar installations or other radio transmitters), can introduce noise, Nsc, to the seismometer signal before it reaches the preamp. These problems are rare and/or intermittent and must be treated on a case by case basis. Noise induced by bad contacts in the calibration circuit relays can also be included here.

Np

Low level internal noise is a normal characteristic of electronic amplifiers, Under normal operating conditions and with a zero level input signal, the amplifier output signal is not zero but a spectrally rich random signal that resembles seismic background noise if viewed through the bandpass filter employed in the seismic system. Because the level of internal noise at the amplifier output depends on the amplifier gain, it is normally "referred" to the amplifier input and characterized by the level of an equivqlent input signal that would match the internal noise at the amplifier output. In a multistage amplifier with moderate gain in the first (or preamplifier) stage, it is the preamplifier input noise level that characterizes the overall amplifier noise and limits the dynamic range of the amplifier.

The J302 and J402 field units employ a fixed gain preamplifier followed by an attenuator and a fixed gain second amplifier stage. In this system the preamplifier input noise is superposed on the seismic signal in the preamplifier. At the amplifier output the preamp input noise has undergone the same amplification as the seismic signal (which includes background earth noišle).

$\mathrm{Na} / \mathrm{a}$

The second amplifier stage follows an attenuator that adjusts the signal to the second stage. The internal noise of the second stage is very low compared to the (amplified) preamp noise at the second stage input; so it can be neglected. 
$\mathrm{Nm}$

The modulator, or VCO (voltage controlled oscillator), which converts the amplified seismic signal to a frequency-modulated audio-frequency subcarrier signal also adds noise to the transmitted signal. Under normal operating conditions, but with a steady DC voltage applied to its input, the modulator produces an output carrier that is not entirely constant in frequency. This problem is analogous to the internal noise of the preamplifier: the stability of the circuit that uses the amplifier output signal to modulate the frequency of the subcarrier signal sets a lower limit on the level of the signal that can be "encoded" and recovered. Moreover, noise introduced by the modulator cannot be identified until the modulating signal is recovered by the discrininator (which also introduces noise).

Nt

When the VCO is not connected to the discriminator by a good short cable but by a complex telemetry system that picks up the modulated subcarriers from a number of stations, combines them into a more complex multiplexed signal, and transports the multiplexed signal via radio links or phone lines to the network recording center, the individual subcarriers can be substantially degraded, with a consequent addition of noise to the seismic signals that they carry. As in the case with VCO noise, the noise introduced by telemetry is not visible until the seismic signal is recovered by the discriminator. Telemetry induced noise can be extremely variable, ranging from a complete interruption of signal due to telemetry failure, through intermittent episodes of noise due to telemetry signal degradation, to continuous near-harmonic noise on one or more subcarrier channels due to multiplexed-signal distortion in faulty electronics or generation of interfering harmonics by non-sinusoidal subcarrier wave forms.

Nd

The discriminator, like the modulator, has an "intemal noise" characteristic that is broadly analogous to the preamp internal noise. Even for a steady unmodulated subcarrier input, the discriminator output signal is not a steady DC level but a spectrally rich random signal that is similar in character to the background earth noise. Moreover, it is in the discriminator output that noise generated by the modulator and by telemetry is first made visible.

The characteristics of the discriminators themselves can be determined in a laboratory environment where very stable modulators directly coupled to the discriminators are substituted for signals from the field. However, the discriminator performs a complex function, and its internal noise depends on many factors, including the frequency passband of the seismic signals it must reproduce.

The principal elements of the discriminator include:

1) an input bandpass filter to select the appropriate modulated subcarrier from the set of signals multiplexed onto a single communications channel, 2) a detector circuit that translates subcarrier-frequency modulation into output voltage level, 
3) an output hi-cut filter that eliminates signal frequencies that are higher than permitted in the system design, including

: the carrier frequency and high frequency noise caused by cross modulation of the processed channel by adjacent channels or carrier noise picked up during transmission.

The irreducible noise in a discriminator is that due to the instability of the detector circuit. The principal sources of additional noise are the instability of the input bandpass filter (if it is an active filter), interchannel modulation (particularly for large deviations of adjacent channels), and modulation noise in the discriminator input filter passband due to poor carrier waveform and/or nonlinear interaction of subcarriers in defective telemetry electronics. The principal noise suppressing element of the system is the output data filter that strongly attenuates frequencies that are higher than the data pass-band.

There is also a systematic chanel to chanel variation in the intrinsic discriminator noise. We use a constant bandwidth multiplexing system( $+/-125$ hz modulation) with 8 equally spaced audio frequency subcarriers $(680,1020$, $\ldots 3060 \mathrm{hz}$ ). In this system the relative modulation of a particular channel is inversely proportional to its center frequency and the intrinsic noise is directly proportional to its center frequency.

Nc

Noise pickup in the cables that connect the discriminator to the $A / D$ converter can further contaminate the seismic signal. Care must be taken to design and test these cables adequately.

$\mathrm{Na} / \mathrm{d}$

The multiplexer and $A / D$ converter that captures the network signals for input to the computer is also a complex electronic device. When installed and configured for operation with the network this device must be carefully tested to insure that it is not adding noise to the seismic signals.

In the analysis that follows it is assumed that Nc and $\mathrm{Na} / \mathrm{d}$ will be controlled by good electronic procedure and testing. Nsc is generally rare and intermittent in occurrence, and it will be excluded from the anaysis. Under normal conditions $\mathrm{Na} / \mathrm{a}$ is also small and will be neglected.

The sources of noise that we will consider further are $\mathrm{Np}, \mathrm{Nm}, \mathrm{Nt}$, and $\mathrm{Nd}$. Unless otherwise specified these symbols refer to noise levels at the discriminator output. Of these sources, only $N p$ is affected by amplifier gain. The other three are independent of amplifier gain, but they are inseperably mixed together in any single experiment. They can be studied separately in a serfes of experiments that focusses first on the discriminator, then on the diseriminator-modulator pair, and then on the modulator-telemetry-discriminator combination.

In order to estimate noise levels at the discriminator output, $N$, due to a combination of noise components, $\mathrm{Ni}$, we shall use the relationship $\mathrm{N}=\mathrm{N} 1+\mathrm{N} 2+\ldots+\mathrm{Nk}$. A number of simple observations about the relationship of $\mathrm{N}$ to the noise components $\mathrm{Ni}$ are in order: 
1) $\mathrm{N}$ will be at least as large as the largest noise component,

2) if the $k$ noise components in $N$ are all equal to $n, N=k n$,

- 3) if an upper limit of $N$, say $N^{*}$, is prescribed and if one of four components is $0.7 \mathrm{~N}^{*}$, then the remaining components of $N$, if all equal, cannot exceed $N^{\prime}=0.1 N^{*}$.

Our goal in Calnet is to achieve a system dynamic range of $60 \mathrm{db}$ if possible. The output level of the discriminators is 4.0 volts $p-p$. Thus, for a $60 \mathrm{db}$ system dynamic range we require that the sum of all noise components at the discriminator output be: $N \leq 4 \mathrm{mv} p-p$. This condition is not met by the present system, but it appears that the combination of $\mathrm{Np}, \mathrm{Nm}$, and $\mathrm{Nd} m i g h t$ be held as low as $4 \mathrm{mv} p-p$. It also appears feasibe to upgrade the telemetry system and its maintenance to reduce $N$ t over many telemetry channels to permit a $60 \mathrm{db}$ system.

The dynamic range of the maximum recordable earthquake signal relative to the background earth noise is another matter. It depends not only on the electronic dynamic range of the system but also on the choice of the ratio of background noise level to electronic noise level at which the system is operated. If the background earth noise level is set to be four times the electronic noise level (by adjustment of the amplifier gain), then the ground-noise to maximum-recordable-earthquake-signal dynamic range is $12 \mathrm{db}$ lower than the dynamic range discussed above.

\section{Analysis of preamp noise versus combined modulator/discriminator noise}

Noise/calibration tests were performed on four J302 field units combined with either J101 or J110 discriminators. The preamp inputs were terminated with $10 \mathrm{~K}$ resistors. Five-hz sine wave signals at 1000 microvolts rms and 10 microvolts rms we re introduced from the standard "test box" on the repair bench. The VCO output signals were introduced to $\mathrm{J} 101$ or J110 discriminators in the repair bench set-up and were dispalyed at appropriate sensitivity levels on a strip chart recorder. Sine wave calibration was provided by the 1000 microvolt rms signal with the attenuator at $36 \mathrm{db}$ and the 10 microvolt rms signal with the attenuator at $0 \mathrm{db}$. Noise analysis was provided by a-series of tests with no input signal (but with a $10 \mathrm{~K}$ resistor across the preamp input) and with the attenuator at $0 d b, 6 d b, 12 d b, 18 d b, 24 d b$, and $42 d b$.

The noise tests provide a means of separating noise introduced before the attenuator (i.e. in the preamplifier) from that introduced after the attenuator (predominantly in the VCO and discriminator). As the tests show, the output signal is dominated by preamp noise at low attenuator settings (high gain) and by vco/discriminator noise at high attenuator settings (low gain). These tests do not separate noise generated in the vCO from that generated in the discriminator. Results from these tests are presented in table 1 and fig 2 .

The preamp input noise for three of the four units is within the nominal design range, but that for the fourth is about twice too high. The average gain of the four units is about $3 \mathrm{db}$ low at $0 \mathrm{db}$ attenuation and $4 \mathrm{db}$ low at $36 \mathrm{db}$ attenuation. The $\mathrm{VCO} / \mathrm{disc}$ noise increases uniformly with increasing center frequency with little regard for discriminator type. The ratio of $\mathrm{vco} / \mathrm{discr}$ noise to center frequency averages 2.21 and increases from 1.96 at $1020 \mathrm{hz}$ to 2.57 at $2720 \mathrm{hz}$. A straight line through these data suggest that the $\mathrm{VCO} / \mathrm{disc}$ 
noise increases from a minimum of 1 to $2 \mathrm{mv} \mathrm{p}-\mathrm{p}$ at the $680 \mathrm{hz}$ channel to 7 to 8 mv p-p at the 3060 channel. The J110 appears to have a slight advantage over the J101 on the higher frequency channels.

To examine the dependence of dynamic range of the preamp/VCO pair on the preamp input noise and on the VCO/discriminator noise, the expected noise levels for several combinations of source noise levels were computed for attenuator settings of 0 to $42 \mathrm{db}$. These results are shown in fig 3 . In table 2 the dynamic range of a system with a $4.0 \mathrm{v} p-p$ maximum output is shown as a function of noise at the discriminator output.

VI Network-wide noise analysis - Dec 20, 1983

To survey the background earth noise and electronic noise characteristics of stations of the central California network, a study was made of the traces just before the onset of waves from the Dec 20, 1983 Cape Mendocino earthquake. A complete set of Siemens playbacks with a sensitivity of $25 \mathrm{mv} / \mathrm{mm}$ and $a 15 \mathrm{hz}, 12 \mathrm{db} /$ octave hi-cut filter had been made for the anaysis of the earthquake and were, therefore, already avallable for the noise study. The overall quality of the records appeared to be representative of network performance over the last several years. Representative records are shown in figs $4 a-d$.

Setting aside cases with many spikes, sporadic severe noise from telemetry dropouts, etc., the noise on Calnet records appears to have three predominant components:

1) rather long period $(0.8$ to $2.5 \mathrm{sec})$ microseisms,

2) high frequency ( $\geq 10 \mathrm{hz}$ ) continuous noise, much of which

is thought to originate in the telemetry,

3 ) cultural noise with frequencies of 2 to $5 \mathrm{hz}$.

The long period microseisms and the high frequency (electronic?) noise are so distinct that both components were measured. When the intermediate period cultural noise dominated the high frequency noise, it was measured instead of the high frequency noise. In fact, some cases of "cultural" noise may be system noise caused by faulty preamp/vco electronics. The $25 \mathrm{mv} / \mathrm{mm}$ sensitivity of the records is rather low for a noise study, particularly at quiet stations. Nonetheless, a useful overall picture of network noise is provided by these records.

Both amplitudes and periods of the microseism and high frequency components of the noise were measured systematically for all functioning stations. These data were analyzed by a program that combined the noise data with an augmented station list and calculated the following:

1) background earth noise (long period) measured at each station, ampm, in millivolts at the discriminator output

2) background earth noise corrected to correspond to a $12 \mathrm{db}$ attenuator setting, ampc, in mv at the discriminator output

3) high frequency (electronic?) noise measured at each

station, in $\mathrm{mv}$ at the discriminator output

4) histograms of ampm, ampc, and ampe

5) histogram of attenuator settings 
6) averages of ampm, ampc, and ampe for each attenuator setting

7) averages of ampm, ampc, and ampe for each telemetry channel

: 8) averages of ampm, ampc, and ampe for each network region -

a. coastal band

b. first inland band 3 west of the San Andreas

c. second inland band

d. San Andreas band

e. wedge between the San Andreas and the Hayward-Healdsburg fault zones

$f$. Coast Range east of $d$ and $e$

g. western edge of the Great Valley

h. Sierra foothills

1. Sierra Nevada, except for the Walker Pass - Coso region

j. Lassen, Shasta, Lake Shasta region

k. Walker Pass - Coso region

1. all other

9) averages of ampm, ampc, and ampe as a function of the number

of radio links in the transmission path.

Attenuation histogram and average noise vs attenuation setting

Field unit attenuation settings are strongly peaked at $12 \mathrm{db}$ and $18 \mathrm{db}$ (table 3 ). The distribution for stations with attenuations from $6 \mathrm{db}$ to $24 \mathrm{db}$ (which includes all non-lo-gain and non-pathological sites) is:

$6 \mathrm{db}, 34$ stations
$12 \mathrm{db}, 129$ stations
$18 \mathrm{db}, 114$ stations
$24 \mathrm{db}, 26$ stations.

There are 48 lo-gain instruments set at $42 \mathrm{db}$.

The average measured background earth noise level (table 3 ) increases slowly from $71 \mathrm{mv}$ at $6 \mathrm{db}$ sites to $111 \mathrm{mv}$ at $24 \mathrm{db}$ sites, while the average adjusted (to $12 \mathrm{db}$ ) background earth noise level increases dramatically from $34 \mathrm{mv}$ at $6 \mathrm{db}$ sites to $444 \mathrm{mv}$ at $24 \mathrm{db}$ sites. The average measired high frequency noise level increases: slowly from $79 \mathrm{mv}$ at $6 \mathrm{db}$ sites to $109 \mathrm{mv}$ at $24 \mathrm{db}$ sites. The $42 \mathrm{db}$ sites are a special case; and they appear to be much quieter than the normal high gain instruments. The measured long period background earth noise was almost too low to estimate (on our $25 \mathrm{mv} / \mathrm{mm}$ playouts) at most of the $42 \mathrm{db}$ sites, with an average of about $9 \mathrm{mv}$. The high frequency noise was also correspondingly low, averaging only $15 \mathrm{mv}$ at the $42 \mathrm{db}$ sites.

The fact that the average high frequency noise and the average background earth noise are very nearly equal at all attenuator settings is inconsistent with our earlier assumption that the earth noise, but not the high frequency noise, was amplified in the preamplifier. This inconsistency suggests that a substantial part of the high frequency noise at the system output actually arises in or in front of the preamplifier. Another explanation of the equality is that, in practise, the ground noise is systematically set high enough to be seen above the prevalling electronic noise. This question is presently

unresolved and requires further work. 
Telemetry channel vs average noise (table 4)

The averages of all three noise values discussed above do not appear to vary significantly from channel to channel.

Region vs average noise (table 5)

Region $a$, along the coast, and region $g$, at the western edge of the Great Valley, are substantially noisier than the average with regard to both background earth noise and high frequency noise. Region h, the Sierra foothills, is the quietest region. Regions $i, j$, and $k$ (the Sierra-Lassen-Shasta region, and Coso-Walker Pass region) have only moderate levels of ground noise but high levels of high frequency noise. The persistent sinusoidal character of the high frequency noise suggests that it arises in the telemetry.

Number of radio links vs average noise level (table 6)

Only the cases of 0,1 , and 2 radio links have sufficient numbers to be significant. High frequency noise is lowest for the case of no radio link, intermediate for the case of two radio links, and largest for the case of one radio link. The differences are not large but are probably significant.

Noise histograms (table 7 and fig 5)

From the noise histograms one can see the following:

1) $44 \%$ of stations have high frequency noise $\leq 40 \mathrm{mv}$, or $40 \mathrm{db}$ below the $4 \mathrm{v}$ maximum output level,

2) $70 \%$ of stations have high frequency noise $\leq 70 \mathrm{mv}$, or about $34 \mathrm{db}$ below $4 \mathrm{v}$.

3) $70 \%$ of stations have ground noise $\leq 100 \mathrm{mv}$, or about $32 \mathrm{db}$ below $4 \mathrm{v}$.

V Analysis of noise on lo-gain stations -Dec. 20, 1983

For stations operating at $42 \mathrm{db}$ attenuation we expect the ground noise and preamplifier noise to be no more than 2 or $3 \mathrm{mv}$ and $1 \mathrm{mv}$, respectively. Thus, the background noise recorded on those channels in the absence of earthquakes should be dominated by VCO, telemetry, and discriminator noise. The noise levels observed for selected $\mathrm{N}-\mathrm{S}$ lo-gain channels are listed in table 8 . The observations were made under a variety of circumstances:

1) measured from the Dec. 20 playbacks through the TRICOM discriminators and a $15 \mathrm{hz}$ hi-cut filter

2) measured with an oscilloscope at the discriminator signal distribution rack in the recording center,

3) measured with an oscilloscope at the $A / D$ input block

in the computer center,

4) digitized and plotted back by hand.

To test the lines from the discriminator output block to the $A / D$ input block, several discriminators were removed and the corresponding cables were

terminated with $125 \mathrm{ohm}$ resistors. The signals then appearing on the $A / D$ input 
were measured with a portable (not grounded to the building) oscilloscope and were digitized and recovered from the PDP 11/44. The various measurements were not simultaneous; so exact agreement cannot be expected. Table 8 supports the following observations:

1) noise levels measured on the Siemens playbacks ranged from $5 \mathrm{mv}$ to $50 \mathrm{mv}$ and averaged $18 \mathrm{mv}$, 2) noise levels measured at the discriminator distribution rack ranged from $10 \mathrm{mv}$ to $100 \mathrm{mv}$ and averaged $43 \mathrm{mv}$, 3 ) noise levels measured at the $A / D$ input ranged from $15 \mathrm{mv}$ to $100 \mathrm{mv}$ and averaged $33 \mathrm{mv}$,

4) when the lines linking the discriminator signal

distribution rack and the $A / D$ input rack were disconnected from the discriminators and terminated with $125 \mathrm{ohm}$ resistors, the signal at the $A / D$ input was $2 \mathrm{mv}$ ( $f$ ive lines were measured),

5) a plot of the digital signals from the previous test (1.e. \#4) showed peak to peak noise signals of $10 \mathrm{mv}$ and $9 \mathrm{mv}$ for the two cases that were plotted (fig 6).

Cases 2 and 3 , above, are sufficiently similar to suggest that the signals appearing at the $A / D$ input are the same as those at the discriminator distribution rack. Case 1 , compared with cases 2 and 3 , suggests that the combination of the TRICOM discriminators and the $15 \mathrm{hz}$ hi-cut filters reduces the noise by about one half. This result is not surprising in view of the average period of $0.07 \mathrm{sec}$ of the noise. Signals read from the scope at the $A / D$ input and those plotted from the digital signals when the discriminators are in place are in good agreement. However, the digitized noise signal is 4 to 5 times larger than the signal measured by the oscillscope at the $A / D$ input for the case in which the discriminators were removed and replaced by $125 \mathrm{ohm}$ resistors.

VI Analysis of system noise during the automatic calibrator cycle

The automatic calibrator in the field unit interrupts the normal seismometer signal once per day to produce the calibration signal illustrated in figure 7:

1) with the seismometer disconnected and the preamp input

terminated with a resistor to preserve balance, the seismometer

is displaced by a calibrated current while, first, an I D code and, then, an interval of system noise only is transmitted, 2) the seismometer is disconnected from the mass deflecting voltage and reconnected to the preamp through a $24 \mathrm{db}$ attenuator. The ensuing signal is the seismometer mass release test superposed on system noise and attenuated ground noise,

3) the preamp is disconnected from the seismometer and connected to a calibrated voltage source that has an internal impedance that preserves preamp balance. The ensuing signal is the system voltage step test superposed on system noise, 4) the preamp is disconnected from the calibrated voltage source and reconnected to the seismometer, and normal operation resumes.

Analysis of the recorded seismic trace before the calibration signal and during the separate stages of the calibration signal permits us to distinguish 
system noise from background noise and to detect such malfunctions as channel-to-channel crosstalk.

-

Calibration signals were played back from 9 tracks of Calnet tape B for March 22 , 1984 ( $f$ ig 8). A 20 minute interval centered on 1200 GCT (nominal calibration time) was played back, and good calibration signals were recovered from 55 out of 72 seismometers. Eighteen of the 55 calibration signals were from lo-gain channels, and 37 were from high-galn channels.

For normal playback of the calibration signals, the Slemens 0scillomink is at the 1.0 sensitivity setting $(1 \mathrm{~mm}=100 \mathrm{mv})$ so that the peak excursions of the seismometer release test and the amplifier step test will be on scale (fig $8 \mathrm{a})$. For analysis of system noise the $1 \mathrm{~mm}=100 \mathrm{mv}$ sensitivity is completely inadequate; so for this study the Siemens sensitivity was set at 0.1

$(1 \mathrm{~mm}=10 \mathrm{mv})$. (fig $8 \mathrm{a}-\mathrm{n})$. To quantify the nolse characteristics of the records before and during the calibration signals, the following measurements were made:

1) peak amplitudes and associated periods of the predominantly long period (ca. $1 \mathrm{sec}$ ) and short period (ca. 0.1 sec.) noise components just before the onset of the callbration signal, 2) peak amplitude and period of the predominant noise following the callbration code transmissiom while the seismometer was disconnected from the system. This noise 16 predominantly short period; so no measurement of a long period component was attemped, 3) large excursions of the trace during the selsmometer release test and amplifier step test (with a consequent large deviation of the carrier of the tested system) a re sometimes accompanied by significant noise on either the tested trace, on other traces, or on both. The peak amplitudes and periods of such disturbances were recorded as $x$-talk interference on the tested trace and as $x$-talk to other traces.

The results of these measurements are presented in table 9, along with channel identification, field attenuator setting, and number of radio links in the transmission path. The entries are grouped according to the tape recorder track from which they were derived. The callbrations summarized in table 9 were made with a $12 \mathrm{db} /$ octave $15 \mathrm{hz}$ hi-cut filter to reduce high frequency noise on the traces.

Additional tests were run to asses the effect of the $15 \mathrm{hz}$ filter on the calibration tests. The results can be summarized as follows:

1) for low noise stations, the noise increases by a factor of 2 when the $15 \mathrm{hz}$ filter $1 \mathrm{~s}$ removed. The increase is somewhat greater for channels with high subcarrier frequencles than for those with low subcarrier frequencies, 2) for noisier stations, the effect is smaller. The noise spectrum for such stations has shifted to lower frequencles, which are not affected by the filter. 
The overall quality of a phone line can be characterized by the average noise level during the "seismometer out" part of the calibration cycle for stations on the line. Excluding clearly abberant stations, the averages for the lines we have studied are:

$\begin{array}{ll}\text { B2 } & 26 \mathrm{mv} \\ \text { B3 } & 14 \mathrm{mv} \\ \text { B5 } & 18 \mathrm{mv} \\ \text { B6 } & 64 \mathrm{mv} \\ \text { B8 } & 12 \mathrm{mv} \\ \text { B9 } & 20 \mathrm{mv} \\ \text { B10 } & 70 \mathrm{mv} \\ \text { B13 } & 15 \mathrm{mv} \\ \text { B14 } & 11 \mathrm{mv}\end{array}$

If we exclude $B 10$ and $B 6$, which have severe problems, the average line noise level is $16 \mathrm{mv}$, $48 \mathrm{db}$ below the maximum signal output level. If we consider only the 14 low-gain components of this sub-set, the average noise level is $9.5 \mathrm{mv}$, $52 \mathrm{db}$ below the maximum signal output level. Previous tests, in which $\mathrm{J} 202$ modulators produced signals that were recorded on the $\mathrm{B}-\mathrm{H} 3700 \mathrm{~B}$ recorder and were then played back through Develco discriminators, using subtractive compenstation, indicate a dynamic range of about $50 \mathrm{db}$ for the system. In these earlier tests the $15 \mathrm{hz}$ filters were not used.

It appears that the system noise in the signals from the normal stations transmitted over well functioning telemetry is approaching the noise level of the tape record/reproduce system. Testing to verify further reduction of system noise will require a quieter record/reproduce system. Potentially, the PDPII/44 data acquisition system will suffice; but the tests on noise at the $A / D$ converter input reported above suggests that the $11 / 44$ system currently is no quieter than the tape system.

VI Summary and conclusions

To attain a dynamic range of $60 \mathrm{db}$ in a system with a maximum output level 4 volts $p-p$, the system noise must not exceed $4 \mathrm{mv} p-p$. Because we are dealing with transient signals, the output noise resulting from the noise generated in separate componenets of the system is the sum of the noise signals that compose it. In the Calnet seismic system there are four principal sources of noise: preamp input noise, modulator noise, telemetry noise, and discriminator noise. In a faulty system, any one of these can far exceed $4 \mathrm{mv}$; so we can hope to attain a $60 \mathrm{db}$ dynamic range only in a finely tuned, well maintained system. Moreover, it appears very difficult to get the discriminator noise below several mv, particularly for the higher frequency channels. The target levels for preamp noise, modulator noise, and telemetry noise must therefore be of the order of $1 \mathrm{mv}$ or less.

The $0 \mathrm{db}$ gain of the nominal Calnet amplifier is $91.3 \mathrm{db}$, or $36.7 \mathrm{~K}$, and the modulator/discriminator gain factor is 4.0/6.0; so the effective preamp-input to discriminator-output "Odb" gain is $24.5 \mathrm{~K}$. In the best of the units we tested the equivalent input preamp noise was $1.4 \mu \mathrm{v} \mathrm{p}-\mathrm{p}$. For the nominal "Odb" gain, such a preamp noise level would produce an output noise level of $34 \mathrm{mv} p-p$. However, we want to operate the system at a much reduced gain to 
enhance the backgound-earth-noise to maximum-output-signal dynamic range. Let us assume a site with a background earth noise 4 times the preamp noise, or $5.5 \mu \mathrm{v}$ p-p. Next let us calculate the signal levels and dynamic range of the system set at $24 \mathrm{db}$ attenuation. The effective gain would be $1.55 \mathrm{~K}$; so the $1.4 \mu \mathrm{v}$ p-p preamp noise would be $2.16 \mathrm{mv} \mathrm{p}-\mathrm{p}$ and the $5.6 \mu \mathrm{v} \mathrm{p}-\mathrm{p}$ ground noise would be $8.64 \mathrm{mv} p-p$ at the discriminator output. In this case the preamp noise and the ground noise would be $65 \mathrm{db}$ and $53 \mathrm{db}$, respectively, below the maximum output. At a noisier site requiring greater attenuation to hold the ground noise below 8 or $9 \mathrm{mv} \mathrm{p}-\mathrm{p}$, the preamp noise would be even farther suppressed. But at a quieter site requiring less attenuation, the preamp noise would be increased at the discriminator output. From table 3 we can calculate the average discriminator output level corresponding to a gain setting of $24 \mathrm{db}$ by dividing AVAMPC (12db gain) by 4. We find that this number for various gain settings is:

$$
\begin{aligned}
& 6 \mathrm{db}-8 \mathrm{mv} \text { p-p, } 34 \text { cases } \\
& 12 \mathrm{db}-20 \mathrm{mv} \mathrm{p}-\mathrm{p}, 129 \text { cases } \\
& 18 d \mathrm{~b}-41 \mathrm{mv} \text { p-p, } 114 \text { cases } \\
& 24 \mathrm{db}-111 \mathrm{mv} \text { p-p, } 26 \text { cases. }
\end{aligned}
$$

Thus, the situation assumed as a test case above $(8.6 \mathrm{mv} p-p$ background earth noise level) in fact corresponds to the 34 quietest network sites on Dec. 20, 1983.

Neglecting telemetry noise for the moment, if we could hold the combined modulator/discriminator noise to $2 \mathrm{mv} p-p$ the total preamp plus modulator/discriminator noise would be about $4 \mathrm{mv} p-p$ for our assumed system operating at $24 \mathrm{db}$ attenuation. Given the difficulty in keeping the mod/disc noise down to $2 \mathrm{mv} \mathrm{p}-\mathrm{p}$, it is extremely important to keep the preamp noise as low as possible. A practical goal for the preamp input noise appears to be about $0.75 \mu \mathrm{v} \mathrm{p}-\mathrm{p}$, which would produce an output noise level of $1.15 \mathrm{mv} \mathrm{p}-\mathrm{p}$ at the $24 \mathrm{db}$ attenuation setting.

In the analysis of network noise just prior to the Dec. 20, 1983 Cape Mendocino earthquake it appears that, on high gain channels, the ratio of long period noise (microseisms?) to short period noise (electronic?) is not a strong function; of attenuator setting. This surprising result suggests either that 1) a large fraction of the short period noise is introduced from the ground or from electronic noise in front of the second amplifier, or 2) attenuator settings are chosen, in practice, so that the background earth noise is approximately equal to the system electronic noise, whatever its source might be.

Analysis of system noise at 55 instruments for which calibration signals were played back from tape recorder B on March 22, 1984, helps to clarify this quetion. The stations analyzed in this set are in a region with higher than average coastal and cultural microseismic noise; and the playback trace sensitivity was $21 / 2$ times higher than for the Dec. 20, 1983 records $(1 \mathrm{~mm}=10 \mathrm{mv}$ instead of $1 \mathrm{~mm}=25 \mathrm{mv})$. Long and short period noise levels and associated periods were read just before the onset of the calibration signals, and short period noise and associated periods were measured during the calibration interval in which the seismometer was disconnected from the preamp. The average long period noise levels (referred to $24 \mathrm{db}$ attenuation) as a function of attenuator setting are quite comparable to those for the Dec. 20, 1983 study: 


$$
\begin{aligned}
& 6 d b-16 m v \text { p-p, } 3 \text { cases } \\
& 12 \mathrm{db}-26 \mathrm{mv} \mathrm{p}-\mathrm{p}, 9 \text { cases } \\
& \text { : } 18 \mathrm{db}-64 \mathrm{mv} \mathrm{p}-\mathrm{p}, 20 \text { cases } \\
& 24 \mathrm{db}-160 \mathrm{mv} \mathrm{p}-\mathrm{p}, 3 \text { cases }
\end{aligned}
$$

The behavior of the short period noise is more complex. Perhaps the most revealing measure of the short period noise is the average noise level at all stations on a given phone line while their respective seismometers were disconnected from their preamps. In order of increasing average noise levels these results are:

$$
\begin{aligned}
& \text { B14 - 11mv p-p } \\
& \text { B8 - 12mv p-p } \\
& \text { B3 - 14mv p-p } \\
& \text { B13 - 15mv p-p } \\
& \text { B5 - 18mv p-p } \\
& \text { B9 - 20mv p-p } \\
& \text { B2 - 26mv p-p } \\
& \text { B6 - 64mv p-p } \\
& \text { B10 - 70mv p-p }
\end{aligned}
$$

The seismic traces for instruments on lines $\mathrm{B} 10$ and $\mathrm{B} 6$ show clear, strong evidence of channel-to-channel cross modulation both before and during the calibration tests, while the traces on other lines generally do not. Moreover, on the very noisy phone lines the level of crosstalk is a function of the ambient carrier frequencies on the line, as is shown by the varying amplitude of crosstalk signals that appear when the large carrier deviations induced by the calibration tests occur. This evidence suggests that the very high short period electonic noise is caused by interaction among carrier signals in the telemetry system. Experience has shown that such problems arise from improper signal levels or malfunctioning hardware on phone lines or radio links and from harmonics generated in the system as a result of non-sine-wave carrier signals from one or more field units served by the telemetry circuit.

However, such telemetry interaction is not the only cause of excessive short period noise. A measure of the excess of short period noise in the complete system (including the seismomoter), over that generated in the electronics and telemetry alone, is the ratio of the short period noise just before the calibration cycle to that during the mass deflection (seismometer out) part of the calibration. For the 55 calibration signals considered here this ratio is less than 1.5 for $60 \%$ of the cases, less than 2.0 for $70 \%$ of the cases, less than 3.0 for $85 \%$ of the cases, and greater than 3 for $15 \%$ of the cases. For the $30 \%$ of cases in the last two categories (ratio greater than 2), the predominant source of short period noise appears to be entering the system in front of the preamplifier and may be either ground noise (perhaps of cultural orifin) or noise picked up in the seismometer cable or in the seismometer connect/disconnect relay in the field unit.

Even for the quieter phone lines examined in the calibration study the system electronic noise (including tape playback noise) is excessive, averaging $16.6 \mathrm{mv} p-p$ on the 7 "normal" lines. This level of noise is only $48 \mathrm{db}$ below the maximum output level. For the quietest individual stations the system noise with the seismometer disconnected appears to be about $5 \mathrm{mv} p-p$, $58 \mathrm{db}$ below the 
maximum output level. System noise levels above this figure very likely result from milder forms of the same problems that produce the very noisy lines. If we could insure that the carrier signals produced in the field units were clean sine waves and if we could manage and maintain the telemetry system to avold serious distortion of the multiplexed carriers during transmission, it seems reasonable to expect that we could reduce the system noise level to $5 \mathrm{mv} \mathrm{p}-\mathrm{p}$ or somewhat less.

The high frequency noise passed by the discriminator is very strongly dependent on its high frequency cutoff. The TRICOM discriminator cuts off ( $30 \mathrm{db} / o c t a v e)$ at $30 \mathrm{hz}$. In the noise tests described here the signals were passed through an additional $12 \mathrm{db} /$ octave $15 \mathrm{hz}$ hi-cut filter. The proposed network discriminator for use with the $11 / 44$ data acquisition system has a $30 \mathrm{db} /$ octave high cut filter with a corner frequency of $20 \mathrm{hz}$. It is anticipated that this discriminator will supress the very high frequency telemetry noise about as well as the TRICOM discriminator followed by the $15 \mathrm{hz} 12 \mathrm{db} /$ octave hi-cut filter.

Tests on the A/D input to the $11 / 44$ show that it sees a noise level of about $10 \mathrm{mv} \mathrm{p}-\mathrm{p}$ when an independent measurement by oscilloscope across the A/D input terminals sees only a $2 \mathrm{mv} p-p$ noise level. This internal(?) noise must be suppressed if we are to approach the $60 \mathrm{db}$ dynamic range. With its present apparent internal noise level, the A/D-11/44 system is no better than the analog tape system.

Finally, we must repeat that most of the noise sources that we have examined must be reduced to very low levels, lmv p-p or less, if the $60 \mathrm{db}$ goal is to be realized. If the preamp, modulator, telemetry, discriminator, and $A / D$

converter each contribute only $2 \mathrm{mv} p-p$ of system noise, then the $10 \mathrm{mv} p-p$ sum will be only 52db below the maximum system output level. Such a condition would be far better than the average network performance at present, but it would not fully utilize the recording potential of the digital system. 
Table 1 Measured values and results from noise tests on four field units. •

Table 2 Discriminator output noise versus system dynamic range in a system with a maximum output of $4 \mathrm{v} p-\mathrm{p}$.

Table 3 Histogram of field attenuator settings and average noise values (and number of cases) as a function of attenuator setting.

Table 4 Telemetry channel versus average noise level.

Table 5 Geographic region versus average noise level. The regions, a through 1, are described in the text.

Table $6 \quad$ Number of radio links versus average noise level.

Table 7 Interval and cumulative histograms of noise levels on Dec. 20, 1983.

Table 8 Noise levels measured on low-gain N-S component channels during December 1983 and January 1984. The different columns correspond to different measurements at different times and places in the output recording system.

Table 9 Noise levels before and during the automatic calibration cycle at instruments on selected tracks from tape recorder $B$ on March 22, 1984. Trace ID and operational parameters are in the first 5 columns. The next three columns show short and long period noise just before the calibration cycle. The last three columns show short period noise during the "seismometer out" part of the cycle as well as $x$-talk interference on the tested trace and $x$-talk to other traces during large deviations of the calibrated trace. 
Figure 1 Schematic diagram of one channel of the Calnet seismic system and designations applied to noise generated in its several parts.

Figure 2 Output noise level versus attenuator setting for four seimic systems.

Figure 3 Noise level versus attenuator setting for various combinations of preamp and vco/discriminator noise. Preamp noise, in uv, is referred to the preamp input. VCO/discriminator noise and total system noise, in mv, are at the discriminator output.

Figure 4 Playouts of representative tape tracks for the December 20, 1983 Cape Mendocino earthquake.

a. Track AlO Stations SW of Clear Lake.

b. Track A2 Stations near Eureka.

c. Track A12 Stations east of San Francisco Bay.

d. Track D5 Stations in the Sierra near Sacramento.

Figure 5 Cumulative histograms of seismic and electronic noise on Dec. 20, 1983. The ordinate shows number of cases and the abscissa shows both noise levels in $\mathrm{mv} p-\mathrm{p}$ and noise levels in $\mathrm{db}$ relative to $4 v$ p-p, the maximum system output.

Figure 6 Hand plots of digitized signals from low-gain stations HPLN and BSGN for the cases:

1) discriminator removed and transmission line terminated with a $125 \mathrm{ohm}$ resistor, and

2) discriminator in place. The corresponding signal levels (mv $p-p)$ as measured on an oscilloscope at the $A / D$ input terminals are shown in parentheses.

Figure 7 Automatic calibration switching circuit diagram and nominal calibration signal, with a description of the phases of the test sequence.

Figure 8 Calibration signals played back under a variety of conditions $f$ rom stations on selected tracks of recorder B on March 22, 1984.

a. Track B10, sens. $=100 \mathrm{mv} / \mathrm{mm}$, $15 \mathrm{hz}$ filter in

b. " sens. $=10 \mathrm{mv} / \mathrm{mm}, \quad$ " $\quad$ in

c. " " out

d. Track B8 sens. $=10 \mathrm{mv} / \mathrm{mm}, \quad 15 \mathrm{hz}$ filter in

e. " " " out

f. " " " " in

g. " " " " " out

h. " " " in/out

i. Track $B 14$, sens. $=10 \mathrm{mv} / \mathrm{mm}, 15 \mathrm{hz}$ filter in

j. " " " out

k. "

1. Track B2 sens. $=10 \mathrm{mv} / \mathrm{mm}$, $15 \mathrm{hz}$ filter in

m. " " " out

n. " " " in/out 
Table 1 Measured values and results from noise tests on four field units.

\begin{tabular}{|c|c|c|c|c|c|c|}
\hline \multicolumn{2}{|c|}{$\begin{array}{l}\text { preamp/VCO } \\
\text { discr } \\
\text { center freq }\end{array}$} & $\begin{array}{c}\mathrm{J} 302 \\
\mathrm{~J} 110 \\
1020 \mathrm{hz}\end{array}$ & $\begin{array}{c}\mathrm{J} 302 \\
\mathrm{~J} 101 \\
1360 \mathrm{hz}\end{array}$ & $\begin{array}{c}\mathrm{J} 302 \\
\mathrm{~J} 110 \\
2380 \mathrm{hz}\end{array}$ & $\begin{array}{c}\mathrm{J} 302 \\
\mathrm{~J} 101 \\
2720 \mathrm{hz}\end{array}$ & $\begin{array}{l}\text { nominal } \\
\text { system }\end{array}$ \\
\hline $\begin{array}{c}\text { signal } \\
\text { lmv rms } \\
\text { lOuv rms } \\
\text { Ouv ( } 10 \mathrm{~K}) \\
\ddot{.} \\
\ddot{.} \\
\text { " }\end{array}$ & $\begin{array}{r}\text { atten } \\
36 \mathrm{db} \\
0 \mathrm{db} \\
0 \mathrm{db} \\
6 \mathrm{db} \\
12 \mathrm{db} \\
18 \mathrm{db} \\
24 \mathrm{db} \\
42 \mathrm{db}\end{array}$ & $\begin{array}{r}640 \mathrm{mv} \text { PP } \\
460 \mathrm{mv} \text { PP } \\
25 \mathrm{mv} \text { PP } \\
10 \mathrm{mv} \text { PP } \\
4.5 \mathrm{mv} \text { PP } \\
3 \mathrm{mv} \text { PP } \\
2.5 \mathrm{mv} \text { PP } \\
2 \mathrm{mv} \text { PP }\end{array}$ & $\begin{array}{r}675 \mathrm{mv} \text { PP } \\
550 \mathrm{mv} \text { PP } \\
50 \mathrm{mv} \text { PP } \\
30 \mathrm{mv} \text { PP } \\
18 \mathrm{mv} \text { PP } \\
10 \mathrm{mv} \text { PP } \\
6 \mathrm{mv} \text { PP } \\
3 \mathrm{mv} \text { PP }\end{array}$ & $\begin{array}{r}725 \mathrm{mv} \text { pp } \\
525 \mathrm{mv} \text { PP } \\
26 \mathrm{mv} \text { Pp } \\
12 \mathrm{mv} \text { pp } \\
7 \mathrm{mv} \text { PP } \\
6 \mathrm{mv} \text { PP } \\
6 \mathrm{mv} \text { PP } \\
5 \mathrm{mv} \text { PP }\end{array}$ & $\begin{array}{r}650 \mathrm{mv} \text { PP } \\
500 \mathrm{mv} \text { PP } \\
30 \mathrm{mv} \text { PP } \\
12 \mathrm{mv} \text { PP } \\
9 \mathrm{mv} \text { PP } \\
8 \mathrm{mv} \text { PP } \\
8 \mathrm{mv} \text { PP } \\
7 \mathrm{mv} \text { PP }\end{array}$ & $\begin{array}{c}1094 \mathrm{mv} \mathrm{pp} \\
690 \mathrm{mv} \mathrm{pP} \\
- \\
- \\
- \\
- \\
- \\
-\end{array}$ \\
\hline $\begin{array}{l}\text { ampl gain at } \\
\text { ampl gain at } \\
\text { ampl magn at }\end{array}$ & $\begin{array}{r}36 \mathrm{db} \text { atn } \\
0 \mathrm{db} \text { atn } \\
0 \mathrm{db} \text { atn }\end{array}$ & $\begin{array}{r}50.6 \mathrm{db} \\
87.8 \mathrm{db} \\
24.5 \mathrm{~K}\end{array}$ & $\begin{array}{r}51.1 \mathrm{db} \\
89.3 \mathrm{db} \\
29.3 \mathrm{~K}\end{array}$ & $\begin{array}{r}51.7 \mathrm{db} \\
88.9 \mathrm{db} \\
27.9 \mathrm{~K}\end{array}$ & $\begin{array}{r}50.8 \mathrm{db} \\
88.5 \mathrm{db} \\
26.6 \mathrm{~K}\end{array}$ & $\begin{array}{r}55.3 \mathrm{db} \\
91.3 \mathrm{db} \\
36.7 \mathrm{~K}\end{array}$ \\
\hline $\begin{array}{r}\text { preamp } \\
\text { noise at } \\
\text { Odb atten ( } p\end{array}$ & $\begin{array}{l}\text { disc out) } \\
\text { ampl out) } \\
\text { reamp in) }\end{array}$ & $\left\{\begin{array}{l}25 m v \mathrm{pp} \\
38 \mathrm{mv} \mathrm{pp} \\
1.6 \mu \mathrm{p} \mathrm{pp}\end{array}\right.$ & $\begin{array}{r}60 \mathrm{mv} \text { pp } \\
90 \mathrm{mv} \text { PP } \\
3.1 \mu \mathrm{N} \text { PP }\end{array}$ & $\begin{array}{r}25 \mathrm{mv} \text { PP } \\
38 \mathrm{mv} \text { PP } \\
1.4 \mu \mathrm{v} \text { PP }\end{array}$ & $\begin{array}{r}25 \mathrm{mv} \text { PP } \\
38 \mathrm{mv} \text { PP } \\
1.4 \mu \mathrm{v} \mathrm{PP}\end{array}$ & $\begin{array}{l}19-43 \mathrm{mv} \text { pp } \\
28-64 \mathrm{mv} \mathrm{PP} \\
.75-1.25 \mu \mathrm{v} \mathrm{PP}\end{array}$ \\
\hline $\begin{array}{l}\mathrm{vco} / \mathrm{disc} \text { n } \\
\text { " noise }\end{array}$ & $\begin{array}{l}\text { (out) } \\
\text { it freq }\end{array}$ & $\begin{array}{c}2 \mathrm{mv} \text { Pp } \\
1.96\end{array}$ & $\begin{array}{c}3 \mathrm{mv} \text { PP } \\
2.21\end{array}$ & $\begin{array}{c}5 \mathrm{mv} p \mathrm{pp} \\
2.10\end{array}$ & $\begin{array}{c}7 \mathrm{mv} p \mathrm{pp} \\
2.57\end{array}$ & - \\
\hline
\end{tabular}

Table 2 Discriminator output noise versus system dynamic range in a system with a maximum. output of $4 \mathrm{v} \mathrm{p}-\mathrm{p}$

$\begin{array}{llllllllll}\text { Noise }(m v ~ p-p) & 18 & 16 & 14 & 12 & 10 & 8 & 6 & 4 & 2\end{array}$ $\begin{array}{llllllllll}\text { Dynamic range (db) } & 46.9 & 48.0 & 49.1 & 50.5 & 52.0 & 54.0 & 56.5 & 6 U .0 & 66.0\end{array}$ 


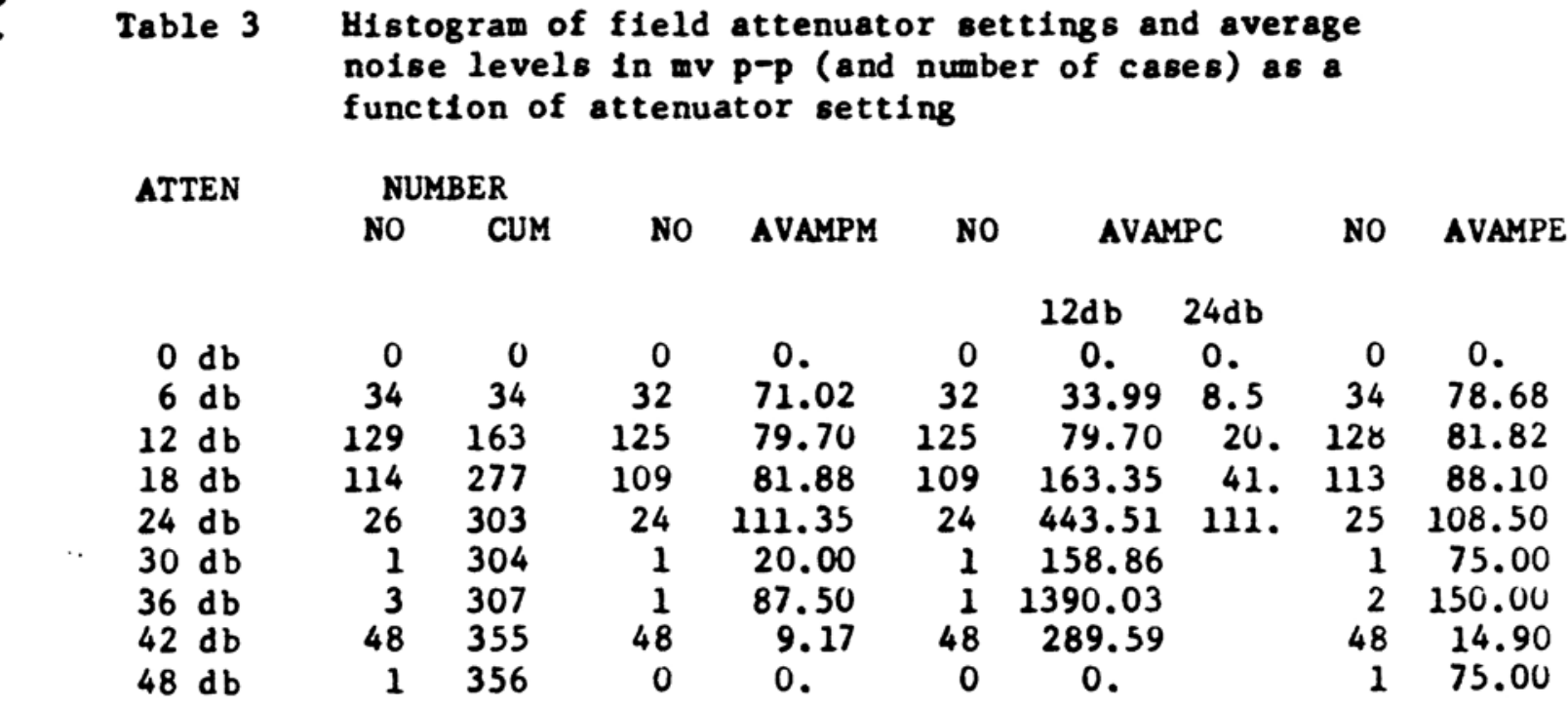

Table 4 Telemetry channel versus average noise levels in mv $p-p$

$\begin{array}{lrrrrrr} & \text { NO } & \text { AVAMPM } & \text { NO } & \text { AVANPC } & \text { NO } & \text { AVAMPE } \\ \text { CHANNEL 1 } & 39 & 84.74 & 36 & 141.06 & 38 & 75.33 \\ \text { CHANNEL 2 } & 45 & 72.67 & 41 & 160.46 & 46 & 104.95 \\ \text { CHANNEL 3 } & 49 & 64.80 & 44 & 120.00 & 51 & 67.16 \\ \text { CHANNEL 4 } & 45 & 66.83 & 43 & 183.54 & 47 & 68.09 \\ \text { CHANNEL 5 } & 45 & 69.78 & 42 & 130.30 & 46 & 74.24 \\ \text { CHANNEL 6 } & 45 & 74.56 & 42 & 139.67 & 51 & 114.02 \\ \text { CHANNEL 7 } & 44 & 72.33 & 42 & 179.73 & 48 & 75.42 \\ \text { CHANNEL 8 } & 44 & 76.59 & 40 & 249.65 & 46 & 72.34 \\ \text { CHANNEL 9 } & 11 & 107.27 & 9 & 137.22 & .11 & 80.68\end{array}$


Table 5 Geographic region versus average noise level in mv p-p. The regions, through 1 , are described in the text.

$\begin{array}{lrrrrrrr} & & \text { NO } & \text { AVAMPM } & \text { NO } & \text { AVAMPC } & \text { NO } & \text { AVAMPE } \\ \text { REGION } & \text { a } & 11 & 150.00 & 10 & 381.03 & 13 & 97.69 \\ \text { REGION } & \text { b } & 19 & 74.47 & 19 & 193.18 & 19 & 43.95 \\ \text { REGION } & \text { c } & 37 & 82.97 & 37 & 219.42 & 37 & 48.85 \\ \text { REGION } & \text { d } & 39 & 81.73 & 39 & 225.24 & 40 & 55.38 \\ \text { REGION } & \text { e } & 35 & 95.36 & 35 & 156.63 & 35 & 77.50 \\ \text { REGION } & \text { f } & 100 & 64.85 & 97 & 156.65 & 102 & 74.04 \\ \text { REGION } & \text { g } & 16 & 117.03 & 12 & 331.99 & 15 & 92.50 \\ \text { REGION } & \text { h } & 21 & 29.40 & 20 & 41.17 & 23 & 51.41 \\ \text { REGION } & \text { i } & 38 & 63.16 & 23 & 109.26 & 46 & 142.01 \\ \text { REGION } & \text { j } & 25 & 54.60 & 23 & 37.64 & 25 & 116.50 \\ \text { REGION } & \text { k } & 15 & 49.00 & 15 & 51.55 & 16 & 106.88 \\ \text { REGION } & 1 & 12 & 72.92 & 10 & 92.91 & 14 & 97.32\end{array}$

Table 6 Number of radio links vs average noise level in mv p-p

$\begin{array}{lrrrrrr} & \text { NO } & \text { AVAMPM } & \text { NO } & \text { AVAMPC } & \text { NO } & \text { AVAMPE } \\ \text { RADLKS 0 } & 263 & 68.98 & 239 & 184.69 & 272 & 68.20 \\ \text { RADLKS 1 } & 67 & 73.36 & 66 & 105.28 & 72 & 111.70 \\ \text { RADLKS 2 } & 30 & 108.17 & 29 & 102.46 & 31 & 96.37 \\ \text { RADLKS 3 } & 2 & 112.50 & 2 & 112.50 & 3 & 183.33 \\ \text { RADLKS 4 } & 3 & 108.33 & 3 & 216.12 & 4 & 268.75 \\ \text { RADLKS 5 } & 1 & 50.00 & 0 & 0 . & -1 & 75.00 \\ \text { RADLKS 6 } & 2 & 53.75 & 1 & 14.96 & -2 & 100.00\end{array}$


- Table 7 Interval and cumulative histograms of noise levels in mv p-p on Dec.20, 1983

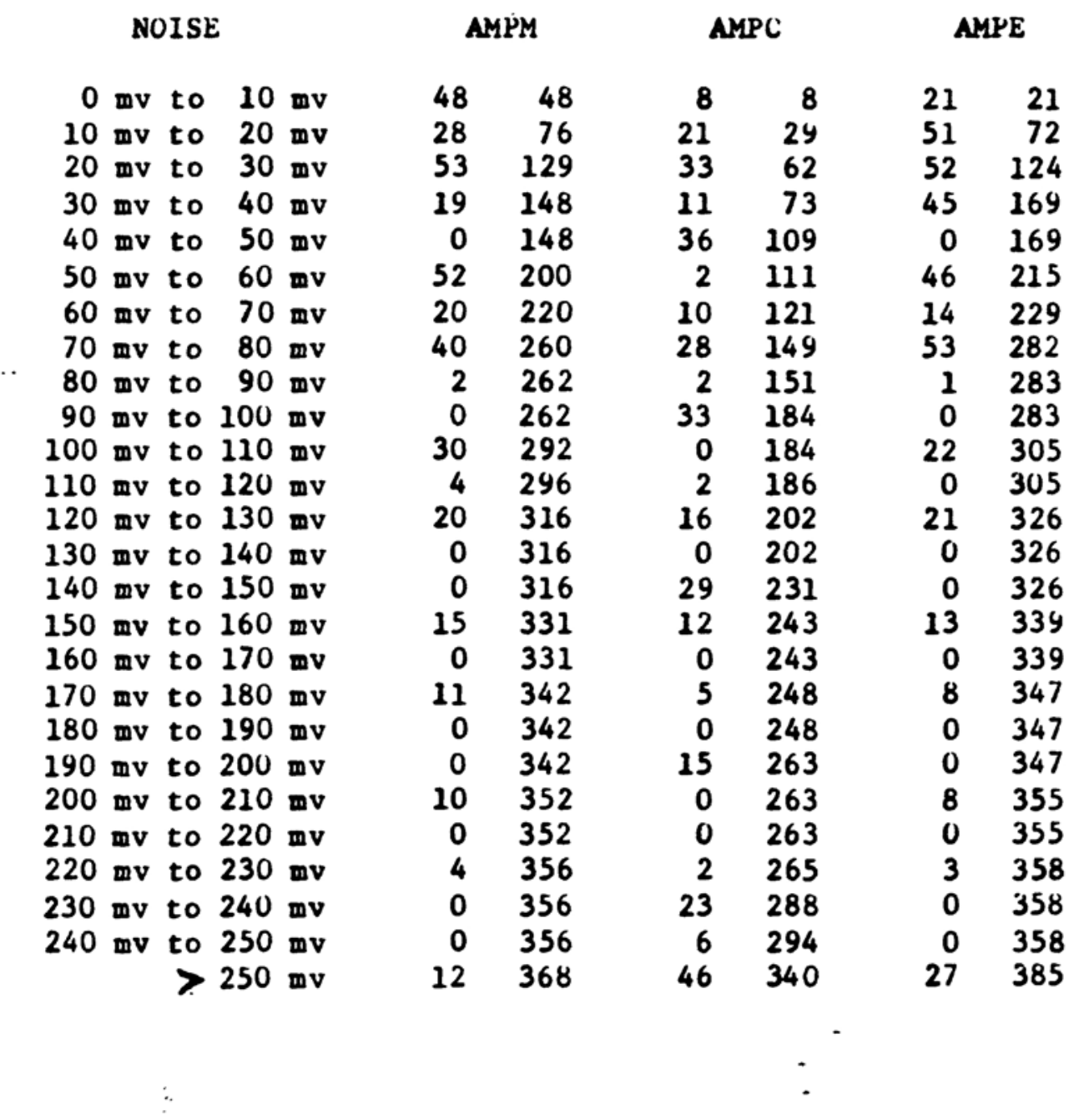




\begin{tabular}{|c|c|c|c|c|c|c|}
\hline & $\begin{array}{r}\text { D } \\
\text { Dec. } 2 \\
\text { 15hz h } \\
\text { AMP(mv) }\end{array}$ & $\begin{array}{l}\text { Dec } 83 \\
20,1983 \\
\text { hi-cut } \\
\text { PER (sec) }\end{array}$ & $\begin{array}{r}\text { Jan } 84 \\
\text { Discr rack } \\
\text { downsta1rs } \\
\text { AMP(mv) }\end{array}$ & $\begin{array}{l}\text { Jan } 84 \\
\text { A/D Input } \\
\text { upsta1rs } \\
\text { AMP(mv) }\end{array}$ & $\begin{array}{c}\text { Jan } 84 \\
\text { A/D Input } \\
\text { (scope) } \\
\text { AMP(mv) }\end{array}$ & $\begin{array}{c}\text { Jan } 84 \\
\text { A/D } \\
\text { output } \\
\text { ANP(mv) }\end{array}$ \\
\hline $\begin{array}{r}\text { STN } \\
\text { KMPN }\end{array}$ & $\begin{array}{c}A M P(m v) \\
38\end{array}$ & $\begin{array}{l}\text { PEK( } 8 \text { (ec) } \\
0.05\end{array}$ & AMIP(mv) & $\begin{array}{c}\text { Ayt (mv) } \\
80\end{array}$ & & \\
\hline NMHN & 25 & 0.08 & 100 & $100 ?$ & & \\
\hline NVEN & 38 & 0.07 & 80 & 30 & & \\
\hline $\begin{array}{l}\text { CDVN } \\
\text { JSFN }\end{array}$ & $\begin{array}{r}8 \\
13\end{array}$ & 0.06 & $\begin{array}{l}30 \\
40\end{array}$ & 30 & & \\
\hline $\begin{array}{l}\text { JSFN } \\
\text { JBLN }\end{array}$ & $\begin{array}{l}13 \\
13\end{array}$ & $\begin{array}{l}0.15 \\
0.14\end{array}$ & 40 & $\begin{array}{l}30 \\
20\end{array}$ & & \\
\hline CAON & 5 & 0.08 & 60 & $100 ?$ & & \\
\hline CALN & 8 & 0.06 & 50 & $40 ?$ & & \\
\hline HPLN & 38 & 0.06 & 60 & 40 & 2 & 10 \\
\hline HQRN & 13 & 0.12 & 60 & 20 & & \\
\hline BAVN & 13 & 0.10 & 10 & 20 & 2 & \\
\hline $\begin{array}{l}\text { BSGN } \\
\text { BPCN }\end{array}$ & $\begin{array}{l}13 \\
13\end{array}$ & $\begin{array}{l}0.25 \\
0.12\end{array}$ & 20 & $\begin{array}{l}15 \\
20\end{array}$ & 2 & 9 \\
\hline BSRN & 8 & 0.05 & 20 & 20 & 2 & \\
\hline BPFN & 20 & 0.06 & & 20 & & \\
\hline PJLN & 13 & 0.05 & 30 & 30 & & \\
\hline PHRN & 13 & 0.10 & 30 & 15 & & \\
\hline PMPN & 25 & 0.11 & & & & \\
\hline PRCN & 50 & 0.20 & & 20 & & \\
\hline PHGN & 13 & 0.06 & 20 & 50 & & \\
\hline PMCN & 13 & 0.05 & 40 & 30 & & \\
\hline BSCN & 5 & 0.05 & & 15 & 2 & \\
\hline AVE & 18 & 0.07 & 43 & 33 & 2 & 9.5 \\
\hline
\end{tabular}


Table 9 Noise levels before and during the automatic calibration cycle at instruments on selected tracks from tape recorder B on March 22, 1984. Trace ID and operational parameters are in the first five columns. The next three columns show short and long period nolse levels just before the calibration cycle. The last three columns show short period nolse during the "selsmometer out" part of the cycle as well as $x$-talk Interference on the tested trace and $x$-talk to other traces during large deviations of the calibrated trace. Nolse levels are in mv $p-p$.

PRE-CALIBRATION NOISE ampl(mv)/period(sec)

$$
\text { LP }
$$

TAPE STN CH ATTN RAD

$\begin{array}{lllll}B 10 & C O S & 3 & 18 & 2\end{array}$

* $\quad$ CBS $4 \quad 18 \quad 3$

" CMP $518 \quad 2$

" HCP $7218 \quad 2$

- BPR 818

B8 CAOV 196

- CAOZ 242

- CAOE 342

" CALZ 442

" CAON 542

- Calv 66

- caln 742

- CALE 842

B5 JSC 118

- JBC 218

" JBZ 418

- HCO 518

- JTG 718

B14 BEM 112

" BMS 318

- BAVZ 442

- BAVN 542

" BAVV 6,6

- BAVE 7: 42

- BEH 818

B13 HJS 212

- BSL 312

- HQRV 412

- HQRZ 542

- HQRN 642

- hQRe 742

* HLT 812

:B9 HPLN 142

- JRR 212

- HPLV 418

- HGS 512

- HPLE 642

- HGW 712

- HPLZ 842
LP (24DB) SP

$30 / 1.7$ (15) $120 / .08$

$600 / .40$ (300) 300/.08

$30 / 1.0$ (15) 90/.06

$140 / .60$ (70) $180 / .06$

$80 / 2.0$ (40) $80 / .06$

$120 / 3.0$ (15) $20 / .06$

$2 / 1.7$ (16) $8 / .06$

- $\quad$ - $13 / .05$

$10 / 2.5$ (80) $10 / .06$

- $\quad-13 / .08$

$230 / 1.7$ (29) $280 / .25$

$5 / 3.0 \quad(40) \quad 7 / .10$

$5 / 2.0 \quad(40) \quad 15 / .06$

$160 / 2.0 \quad(80) \quad 30 / .06$

$200 / 1.6$ (100) $170 / .16$

$190 / 1.3$ (95) $60 / .05$

420/1.1 (210) 80/.10

200/1.0 (100) 30/.06

$70 / 1.8 \quad(17) \quad 30 / .06$

$40 / 1.4$ (20) 20/.07

- $\quad-8 / .07$

- $\quad 8 / .07$

$100 / 1.3$ (13) $15 / .05$

- $\quad 8 / .07$

$60 / 1.4$ (30) $40 / .06$

$80 / 1.0$ (20) $130 / .04$

$230 / 1.4$

(29) $200 / .10$

$110 / 1.5$

(27)

$40 / .04$

$10 / .35$

- $\quad-$

- $\quad-$

$60 / 1.4$ (15)

$$
-
$$

$100 / 2.5$

$150 / 1.6$

(25)

(75)

$10 / .35$

$10 / .35$

$30 / .04$

$80 / .05$

$40 / .06$

$50 / 1.4$

(13)

$160 / .20$

$25 / .18$

$15 / .20$

$140 / 1.6(70)$

$60 / .06$
CALIBRATION TEST

ampl(mv)/period(sec)

\section{SEIS}

OUT

$80 / .06$

$100 / .06$

$100 / .10$

$25 / .06$
$30 / .35$

$70 / .08$

$70 / .06$

$15 / .05$

$5 / .10$

$15 / .05$

$8 / .06$

$8 / .14$

$18 / .12$

$12 / .06$

$15 / .06$

$18 / .06$

$10 / .06$

$10 / .05$

$30 / .13$

$20 / .06$

$15 / .15$

$5 / .05$

$10 / .06$

$5 / .05$

$15 / .12$

$5 / .08$

$20 / .10$

$30 / .06$

$20 / .07$

$10 / .35$

$10 / .35$

$10 / .35$

$25 / .10$

$70 / .05$

$25 / .10$

$25 / .14$

$10 / .30$

$15 / .18$

X-TALK

INTERF OTHER CH

220/.06 60-240/.07

$220 / .09$

$80 / .07$

$130 / .06$

$150 / .06$

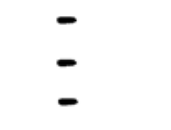

slight

$25 / .10$

$25 / .10$

-

-

-

$20 / .12$

-

$15 / .14$

20/.11

$50 / .05$

$70 / .08$

slight

$30 / .09$

$15 / .06$

$50-180 / .12$

$100-300 / .06$

$70-210 / .07$

$150 / .06$

$25 / .06$

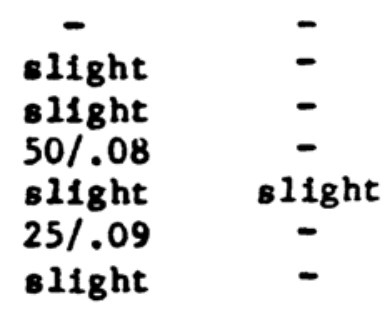




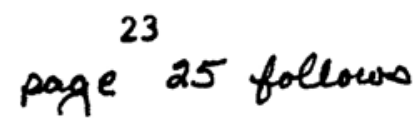

Table 9 continued

\begin{tabular}{|c|c|c|c|c|c|c|c|c|c|c|}
\hline & & & & & $\begin{array}{l}\text { PRE-CALI } \\
\text { ampl(mv) }\end{array}$ & $\begin{array}{l}\text { BRATION } \\
\text { /period }\end{array}$ & $\begin{array}{l}\text { NOISE } \\
(\mathrm{sec})\end{array}$ & $\begin{array}{l}\text { CALI } \\
\text { ampl( }\end{array}$ & $\begin{array}{l}\text { BKATION TI } \\
\text { v)/period }\end{array}$ & sec) \\
\hline & & & & & & & & SEIS & X-TALK & X-TALK \\
\hline TAPE & STN $C$ & $\mathrm{CH}$ & ATTN & RAD & LP & (24DB) & SP & OUT & INTERF & OTHER CH \\
\hline B6 & JBLV & 1 & 18 & 0 & $100 / 2.0$ & (50) & $100 / .05$ & $70 / .06$ & $?$ & $?$ \\
\hline * & HSL & 2 & 18 & 0 & $100 / 1.2$ & (50) & $100 / .07$ & $80 / .07$ & $?$ & $?$ \\
\hline 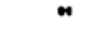 & JRG & 6 & 18 & 0 & $120 / 1.4$ & (60) & $80 /$. & $50 / .06$ & $?$ & $?$ \\
\hline$\infty$ & MYL & 7 & 18 & 2 & $90 / .50$ & (45) & $70 / .05$ & $70 / .07$ & $?$ & $?$ \\
\hline 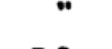 & JBLE & 8 & 42 & 0 & - & - & 60 & $50 / .07$ & $?$ & $?$ \\
\hline B3 & JSFV & 1 & 24 & 0 & $120 / 1.8$ & (120) & $20 / .05$ & $5 / .10$ & - & slig \\
\hline & JSFN & 2 & $42 ?$ & 0 & $100 / 1.6$ & $(800)$ & $5 / .07$ & $5 / .06$ & - & - \\
\hline$"$ & JPS & 3 & 18 & 0 & $290 / 1.8$ & (145) & $15 / .08$ & $10 / .08$ & s11ght & - \\
\hline "u & JLT & 5 & 24 & 0 & $170 / 2.0$ & $(170)$ & $60 / .08$ & $30 / .05$ & slight & - \\
\hline & JBG & 7 & 24 & 0 & $310 / 1.3$ & (310) & $20 / .08$ & $20 / .16$ & sl1ght & - \\
\hline & JSFZ & 8 & 42 & 0 & $10 / 1.6$ & $(80)$ & $15 / .10$ & $15 / .15$ & - & - \\
\hline B2 & CMR & 1 & 12 & 0 & $70 / 1.8$ & (17) & $25 / .07$ & $20 / .06$ & $40 / .09$ & - \\
\hline & CDO & 3 & 24 & 0 & $50 / 3.0$ & (50) & $40 / .07$ & $35 / .07$ & - & - \\
\hline 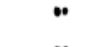 & CMO & 4 & 18 & 0 & $70 / 1.2$ & (35) & $60 / .08$ & 20/.09 & $40 / .06$ & - \\
\hline & CVA & 5 & 18 & 0 & $20 / 2.2$ & (10) & 201. & $30 / .09$ & slight & - \\
\hline " & $\mathrm{CSH}$ & 8 & 18 & 1 & $50 / 2.0$ & (25) & $70 / .05$ & $25 / .0 y$ & - & - \\
\hline
\end{tabular}


Fig 125

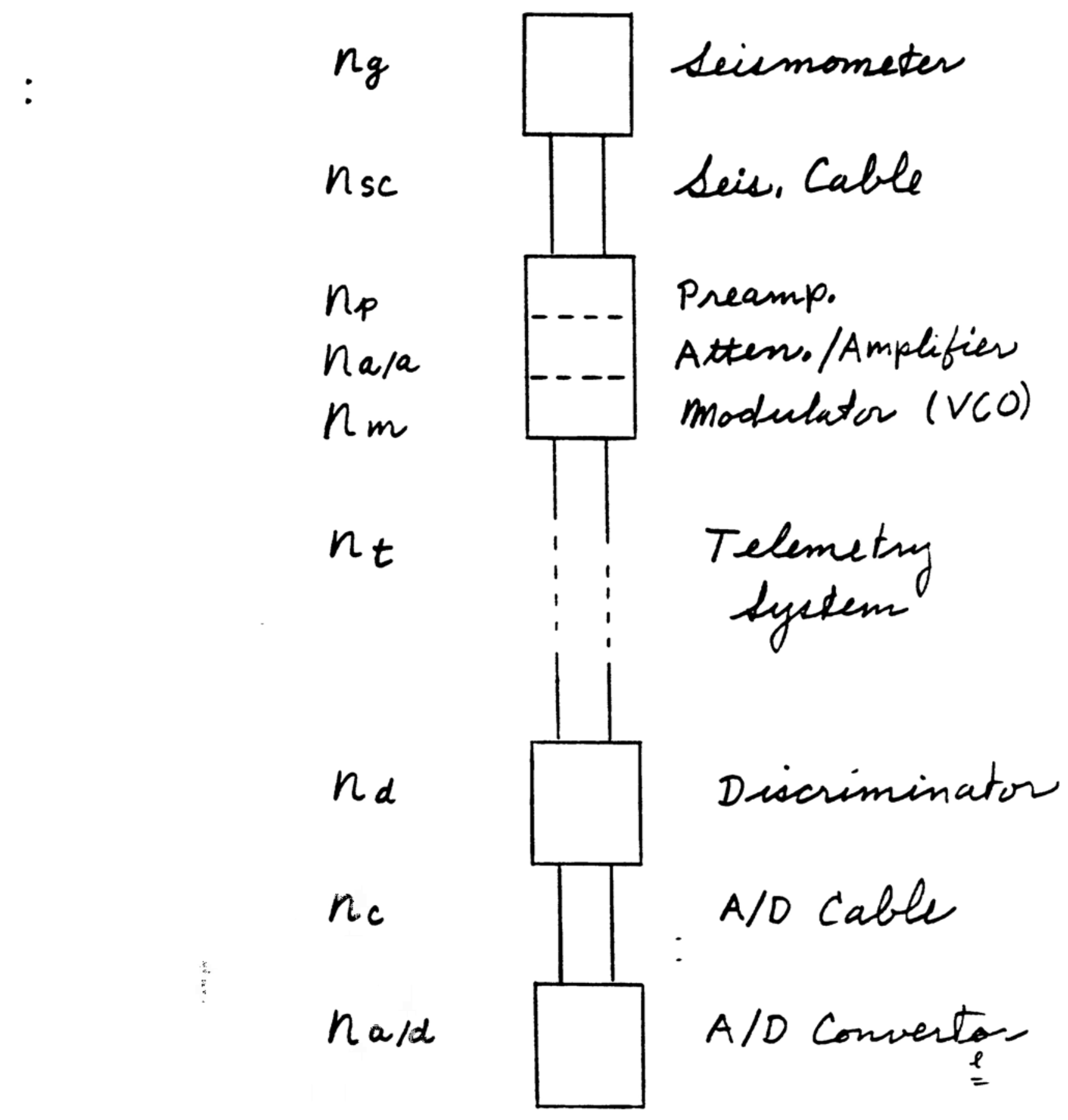




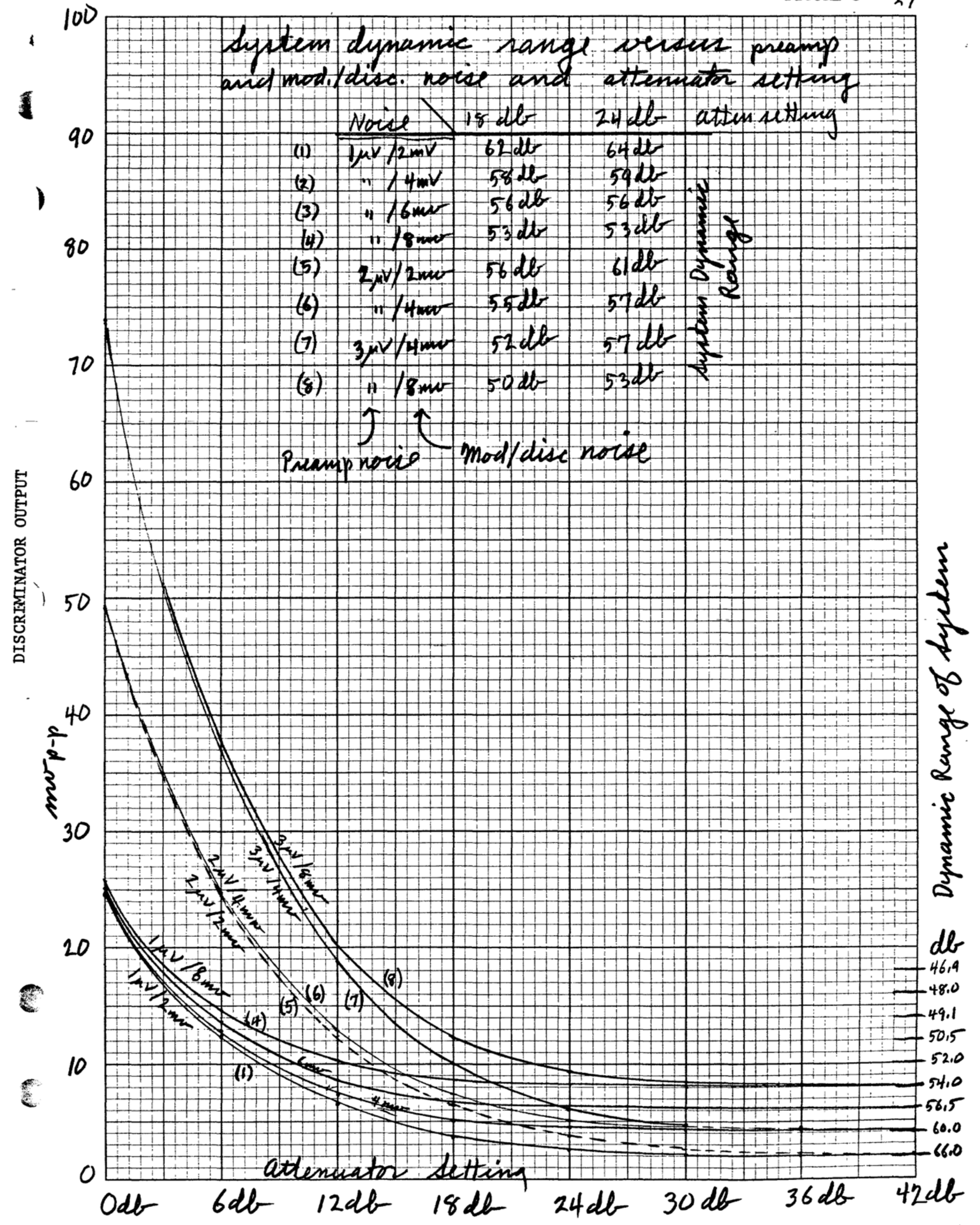


$5-7-7-$

Fig $4 a$ a NTB iPDo

$$
\text { । }
$$

1

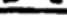

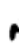

NMW
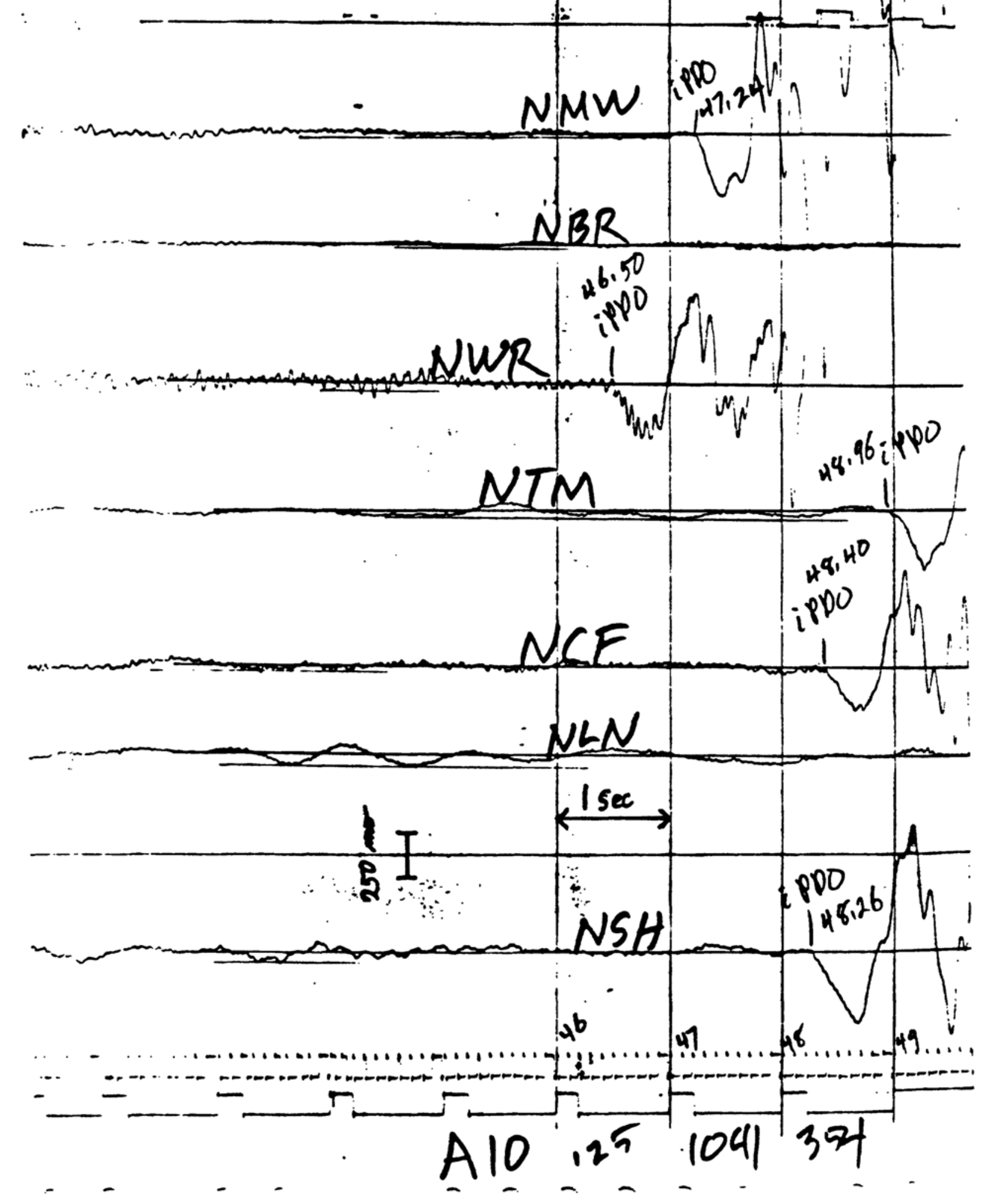


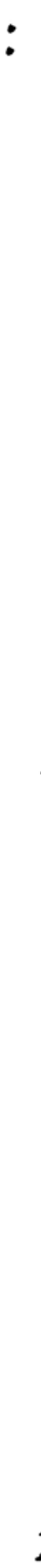
Fig $4 b$

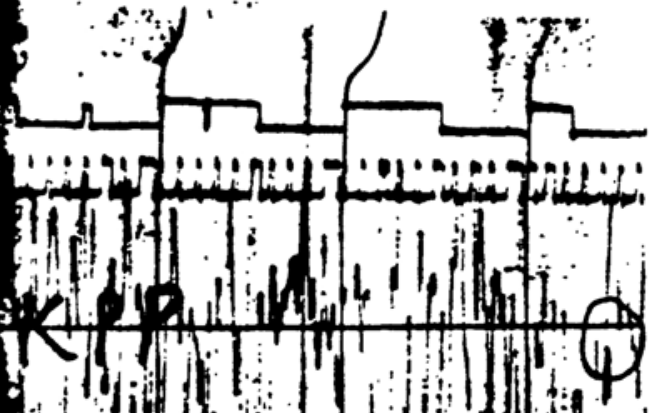
${ }^{\prime \prime}=12$

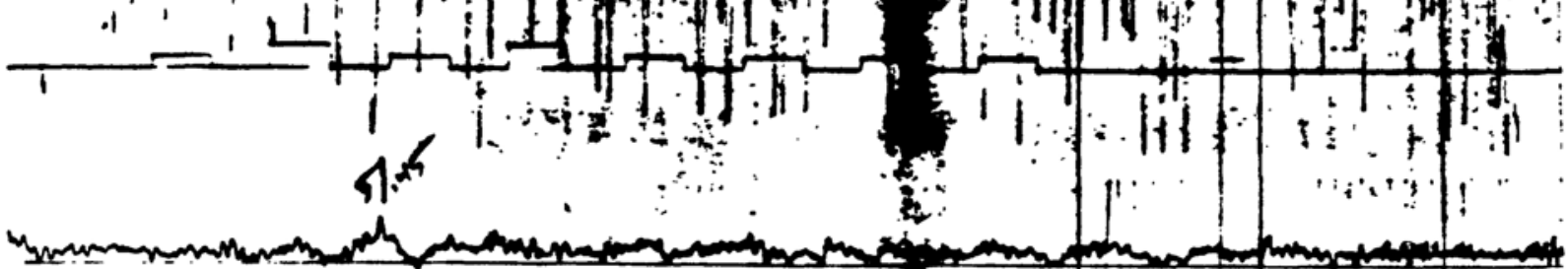

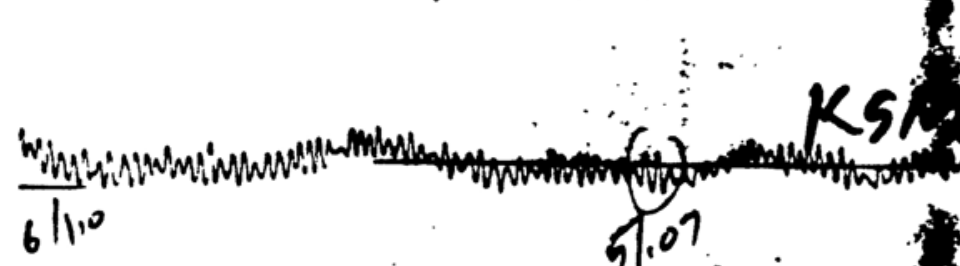

6|1.4

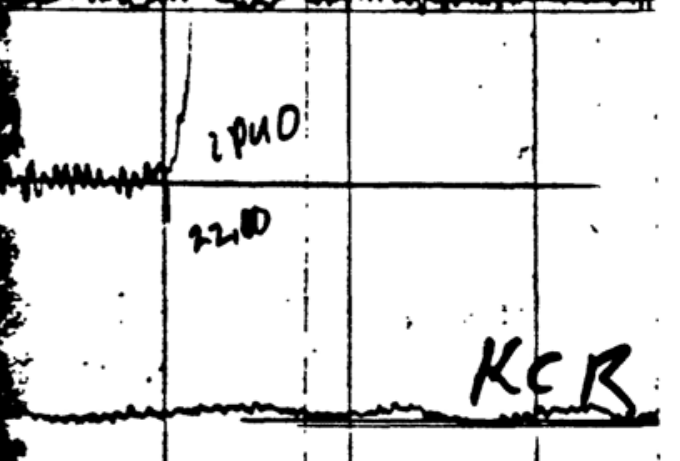

-

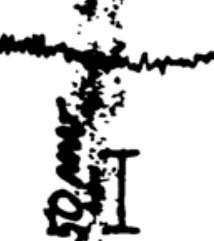

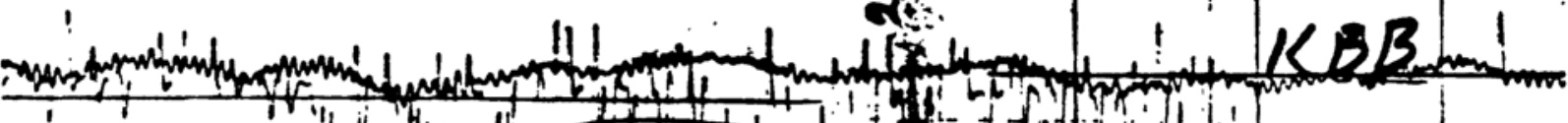

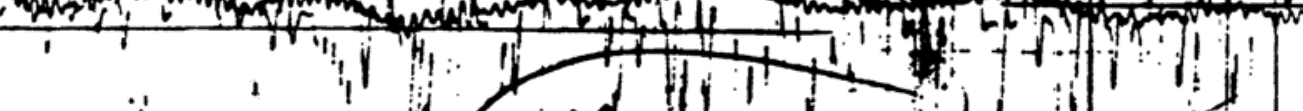

$\frac{1 \sec }{1}$

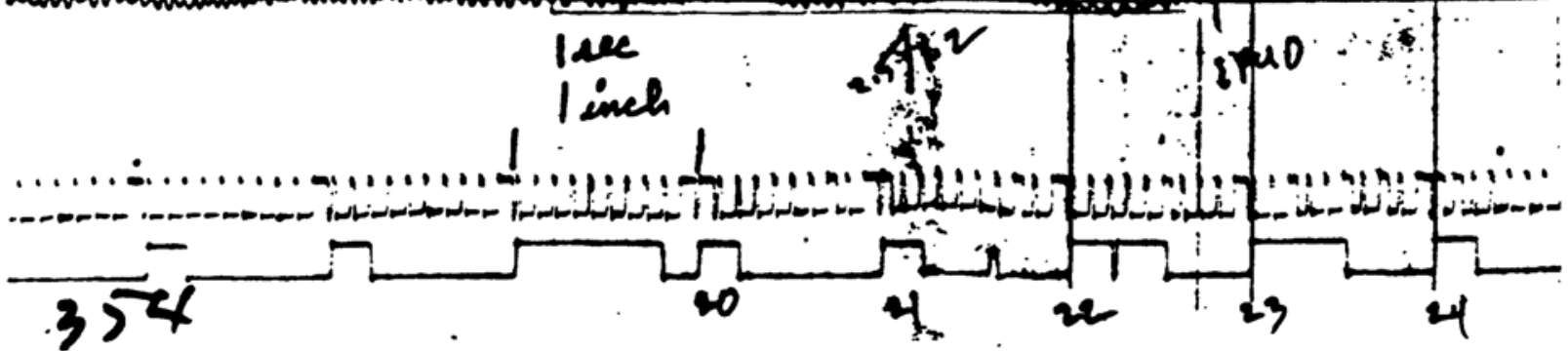




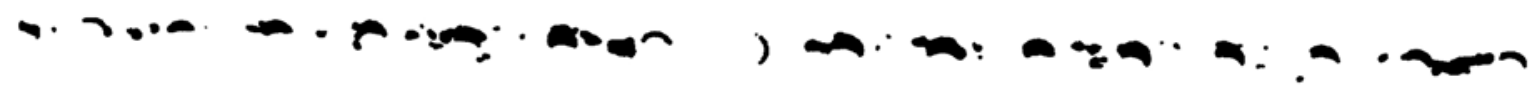
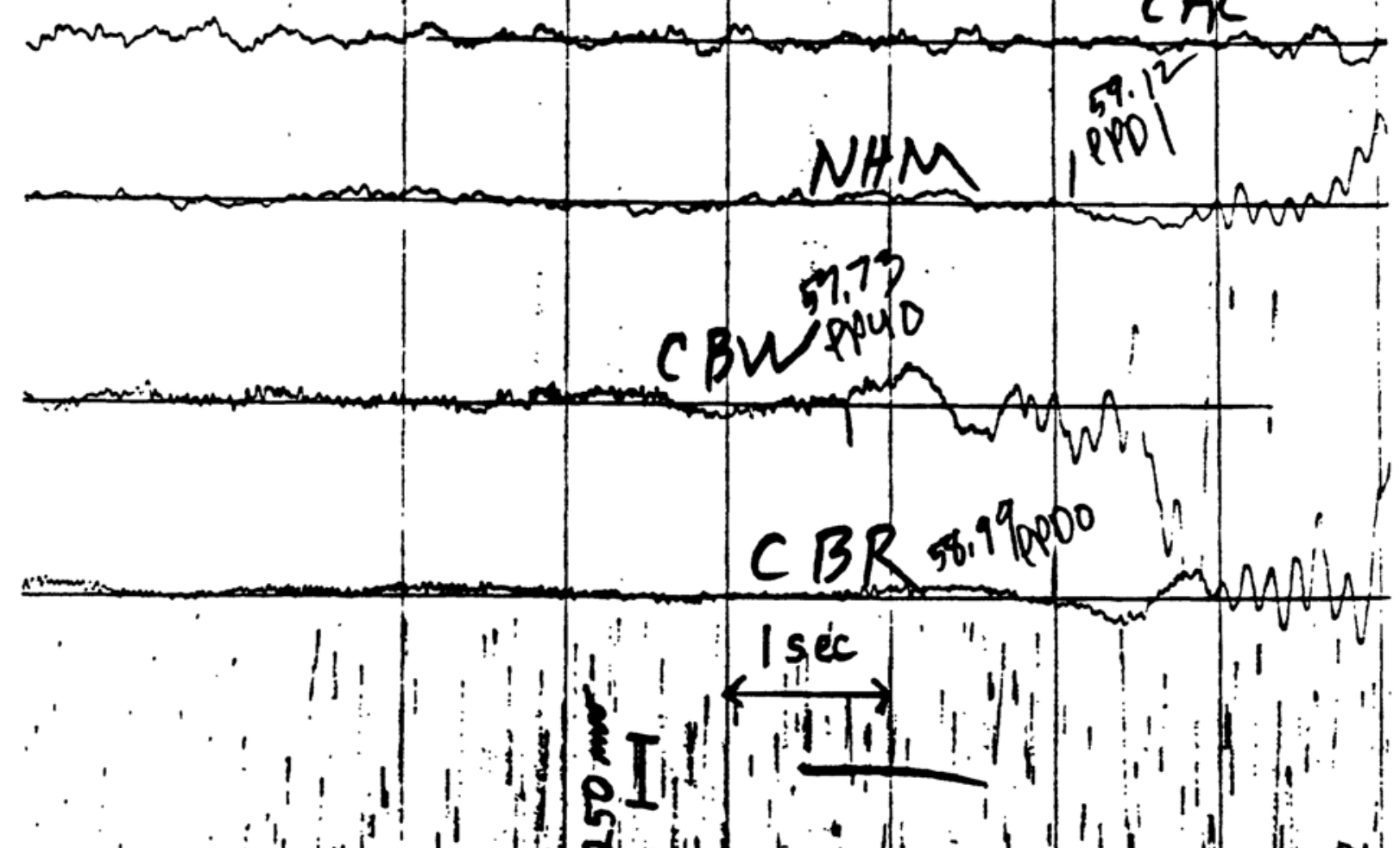

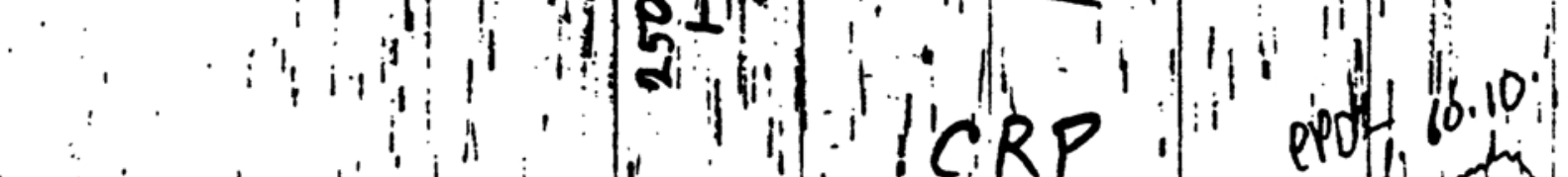
r.

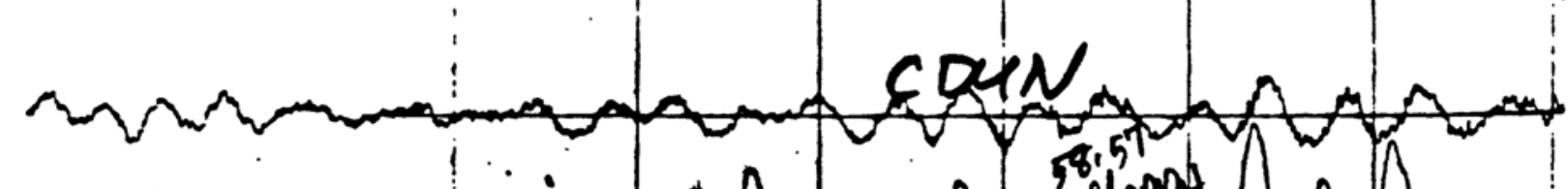

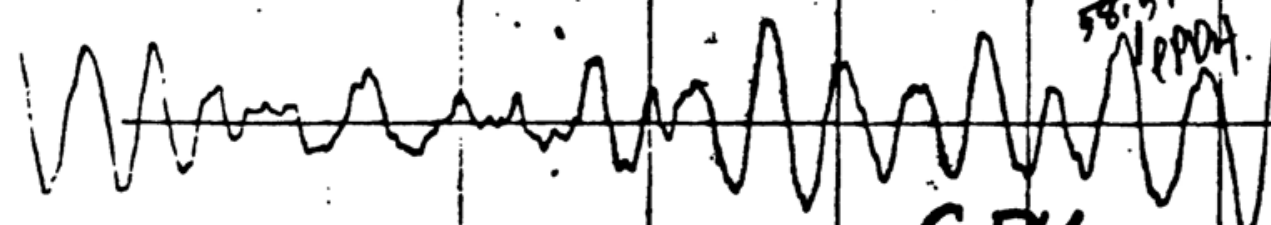

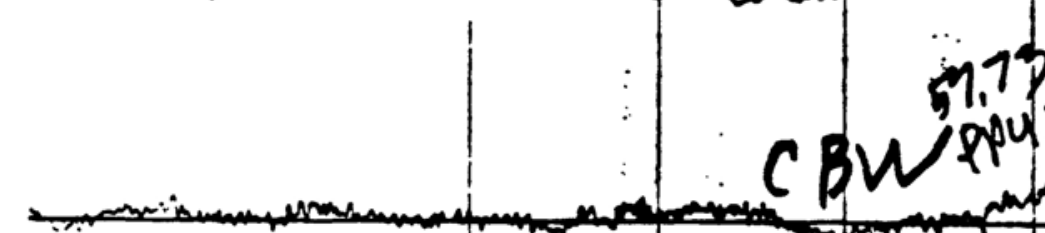




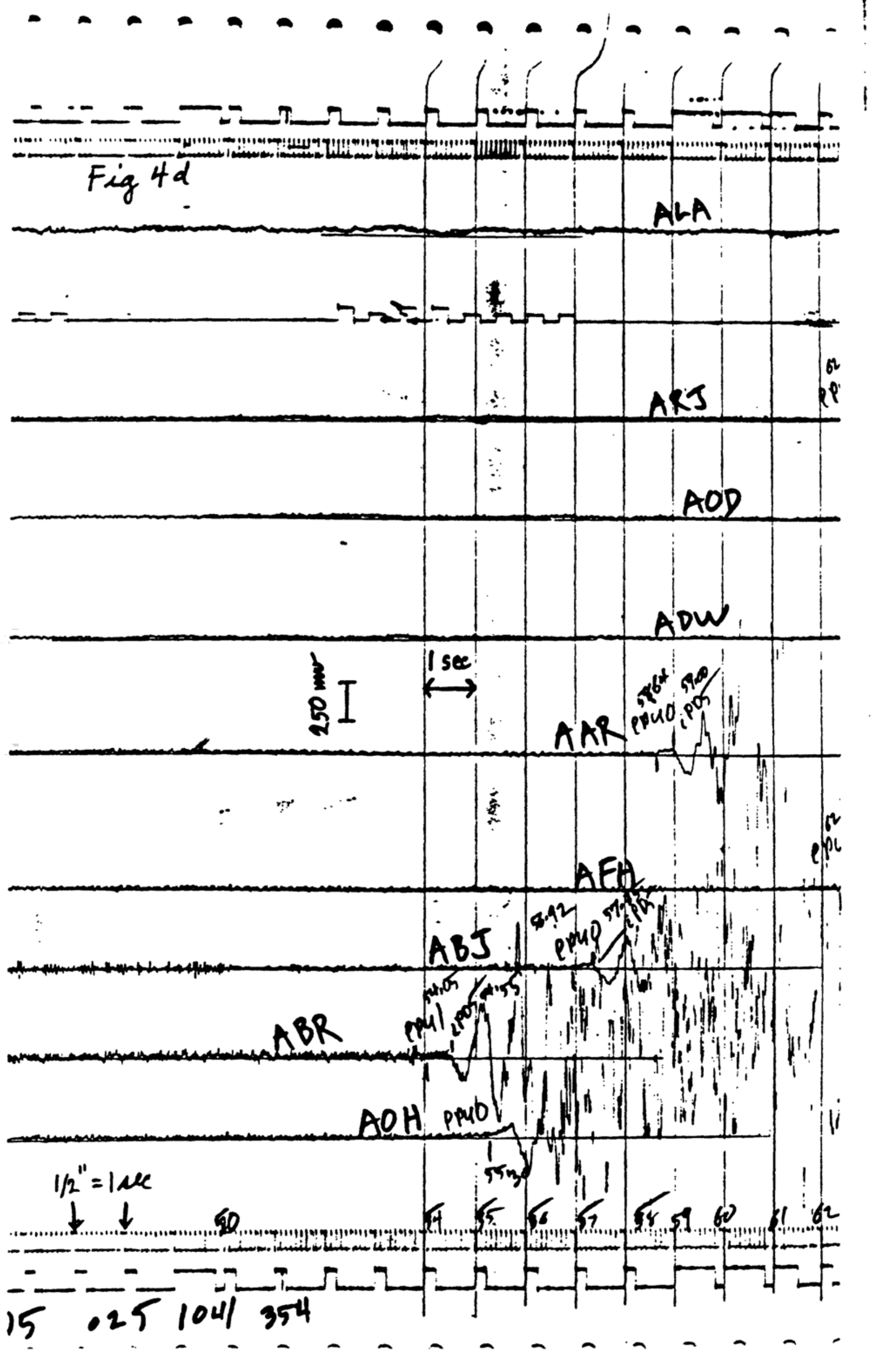


FIGURE 5

32

Cumulates histograms

of seismic and

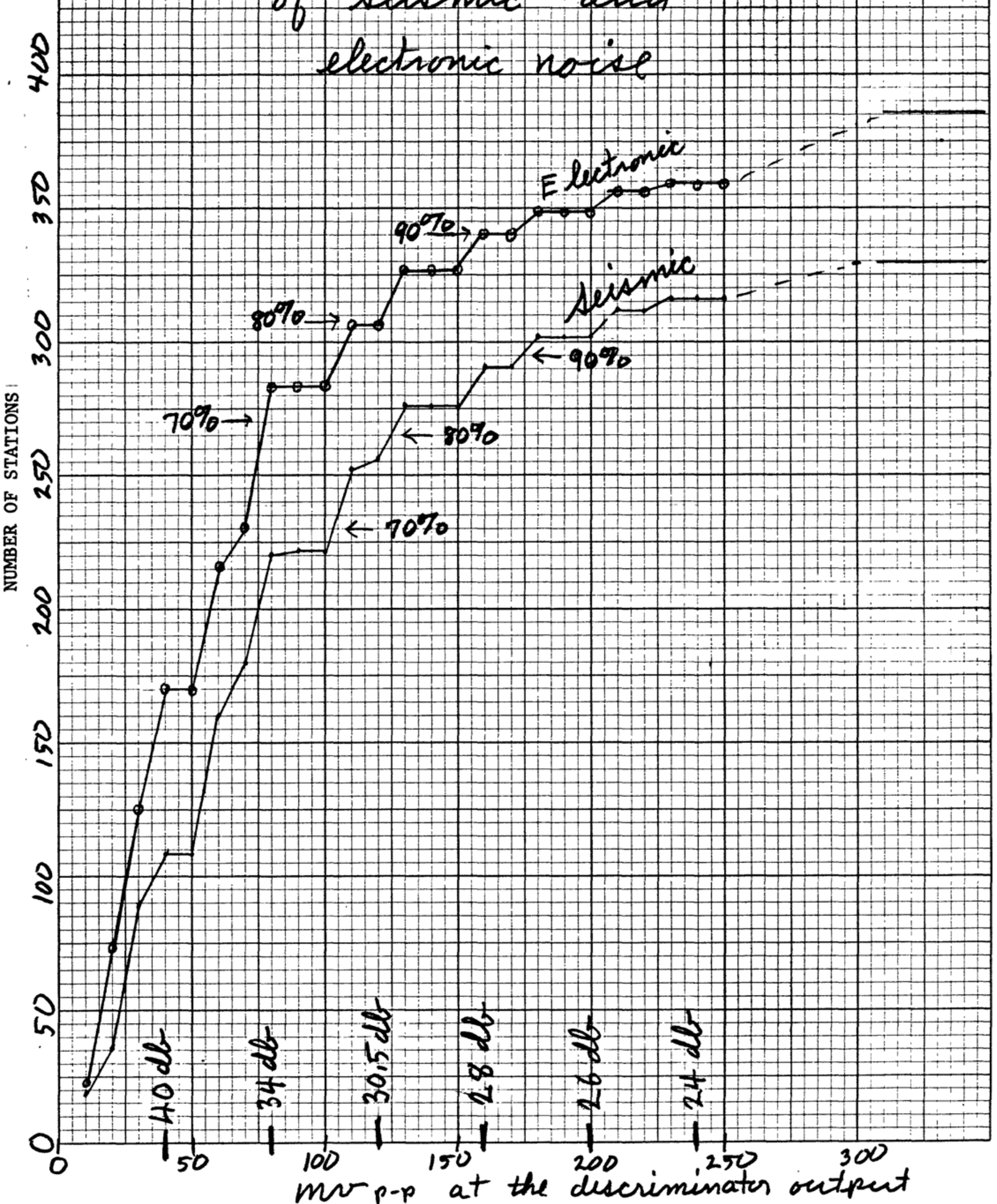




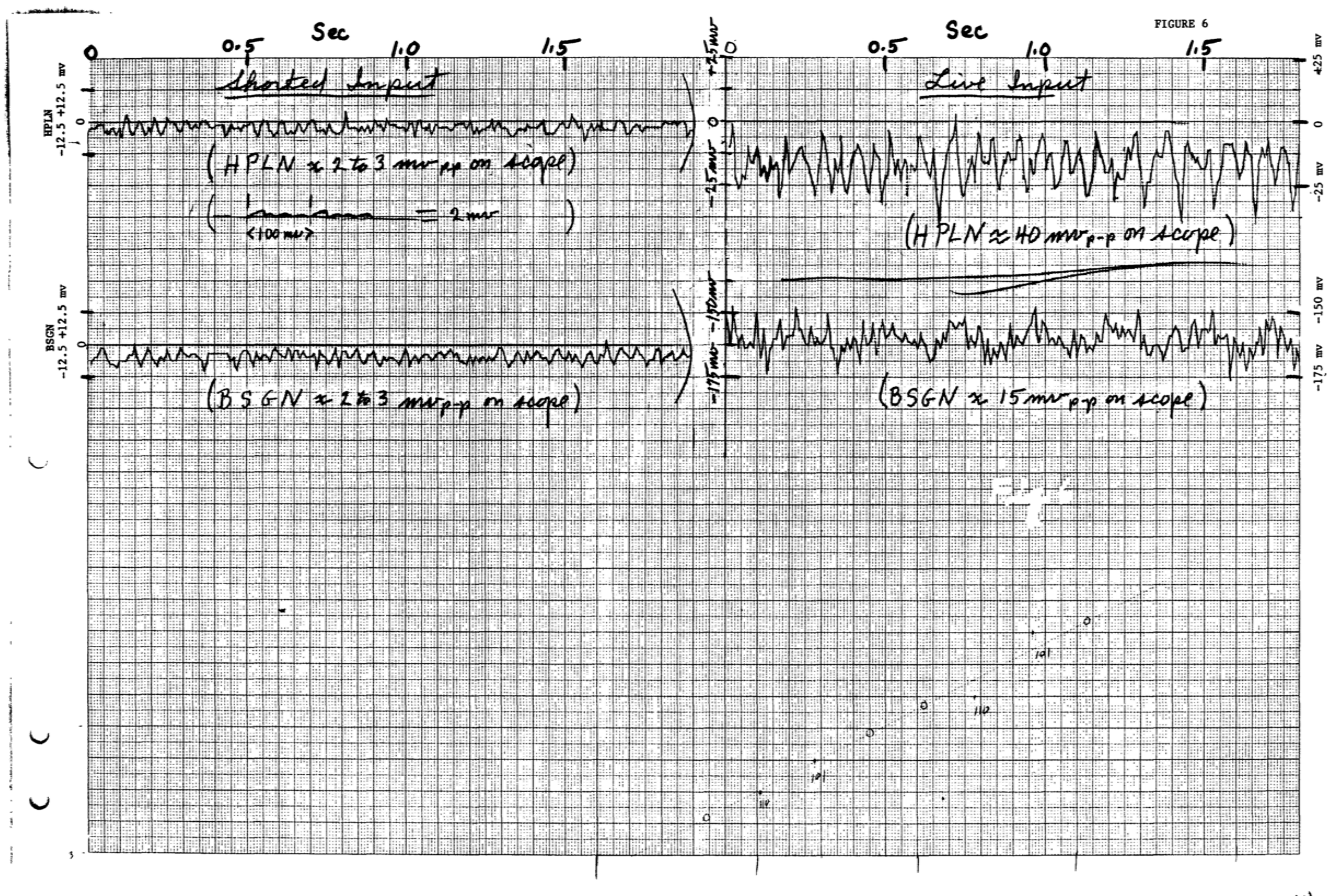


34

$$
\text { C5 cal ib }
$$

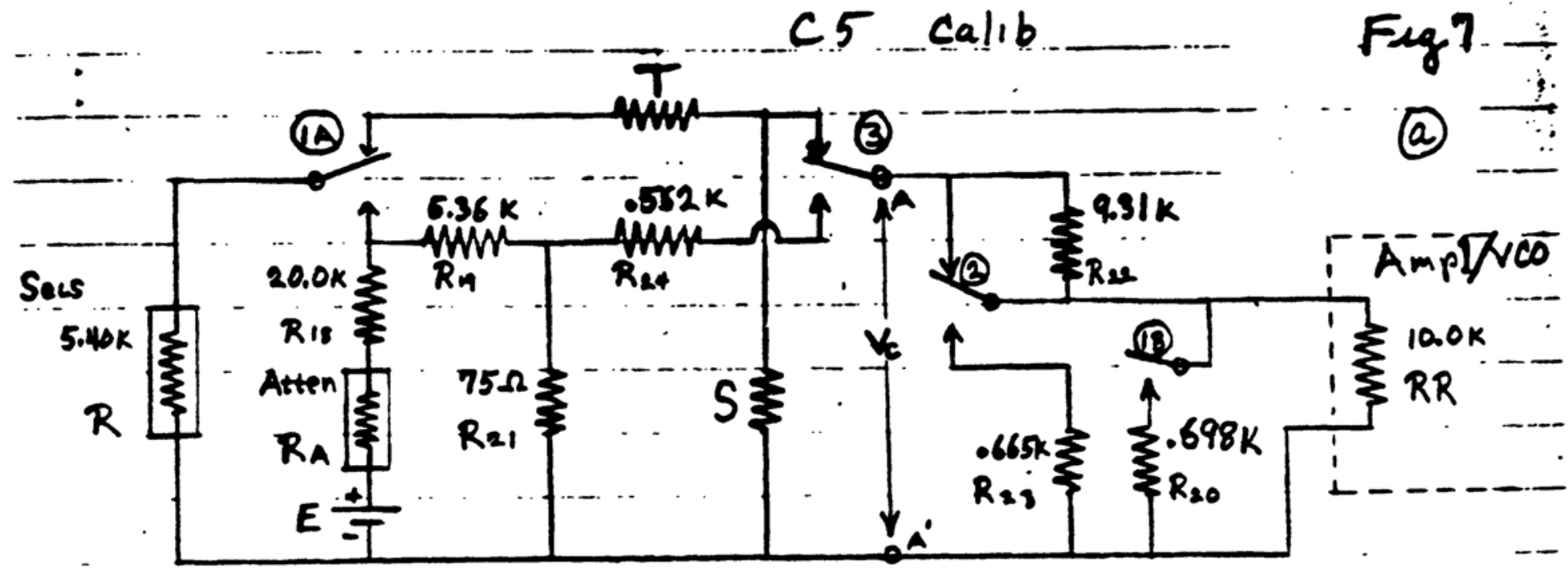

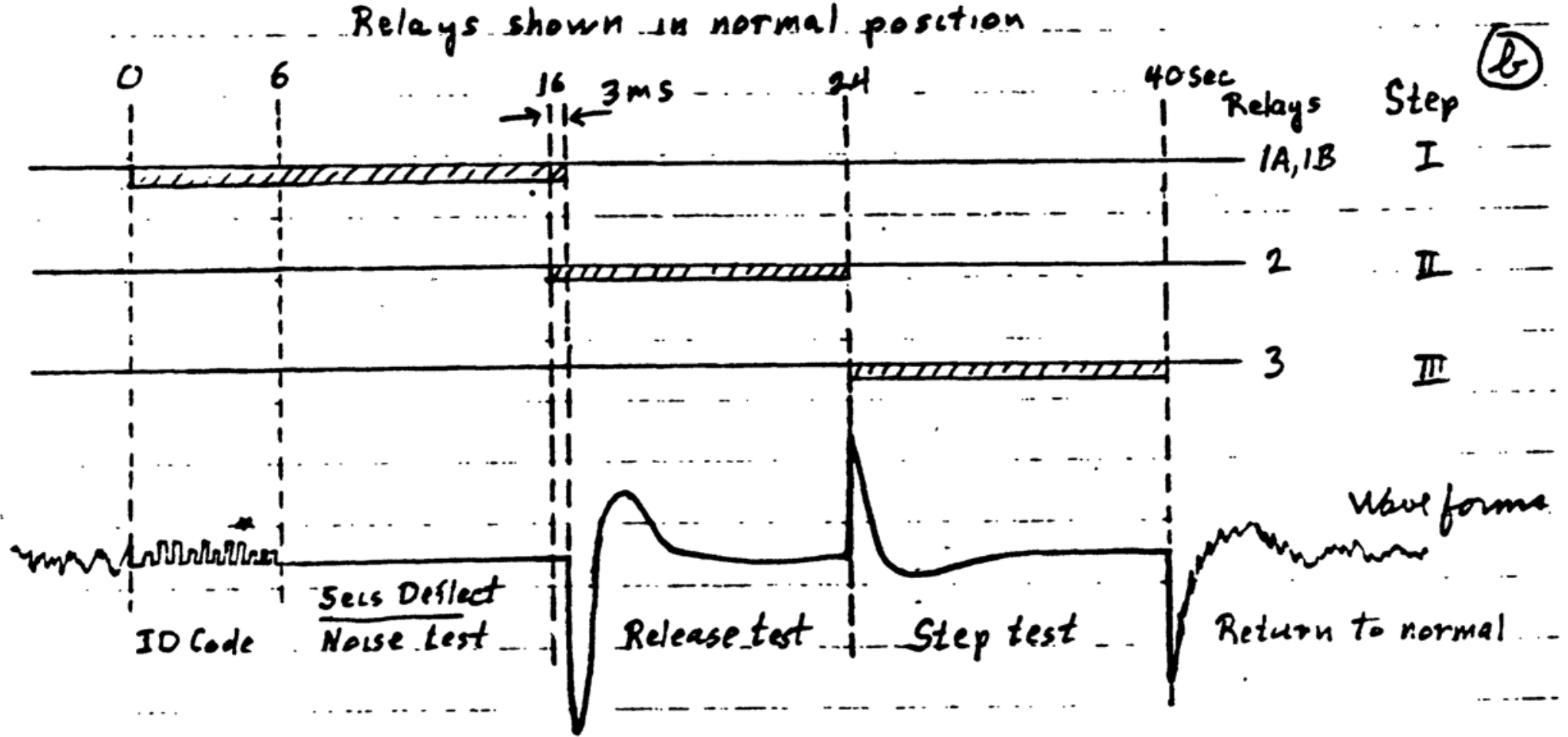

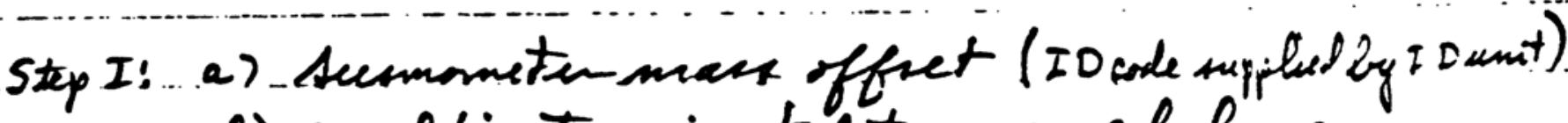

b) amplifierterminats to preserve balance

II: a) $24 \mathrm{db}$ pad inserted

b). Mass released $3 \mathrm{~ms}$ later

III a) Voltage step applied t amplifier

b Station returned to nomad 16 sec later

* Input directly to VCO by code generator unit 


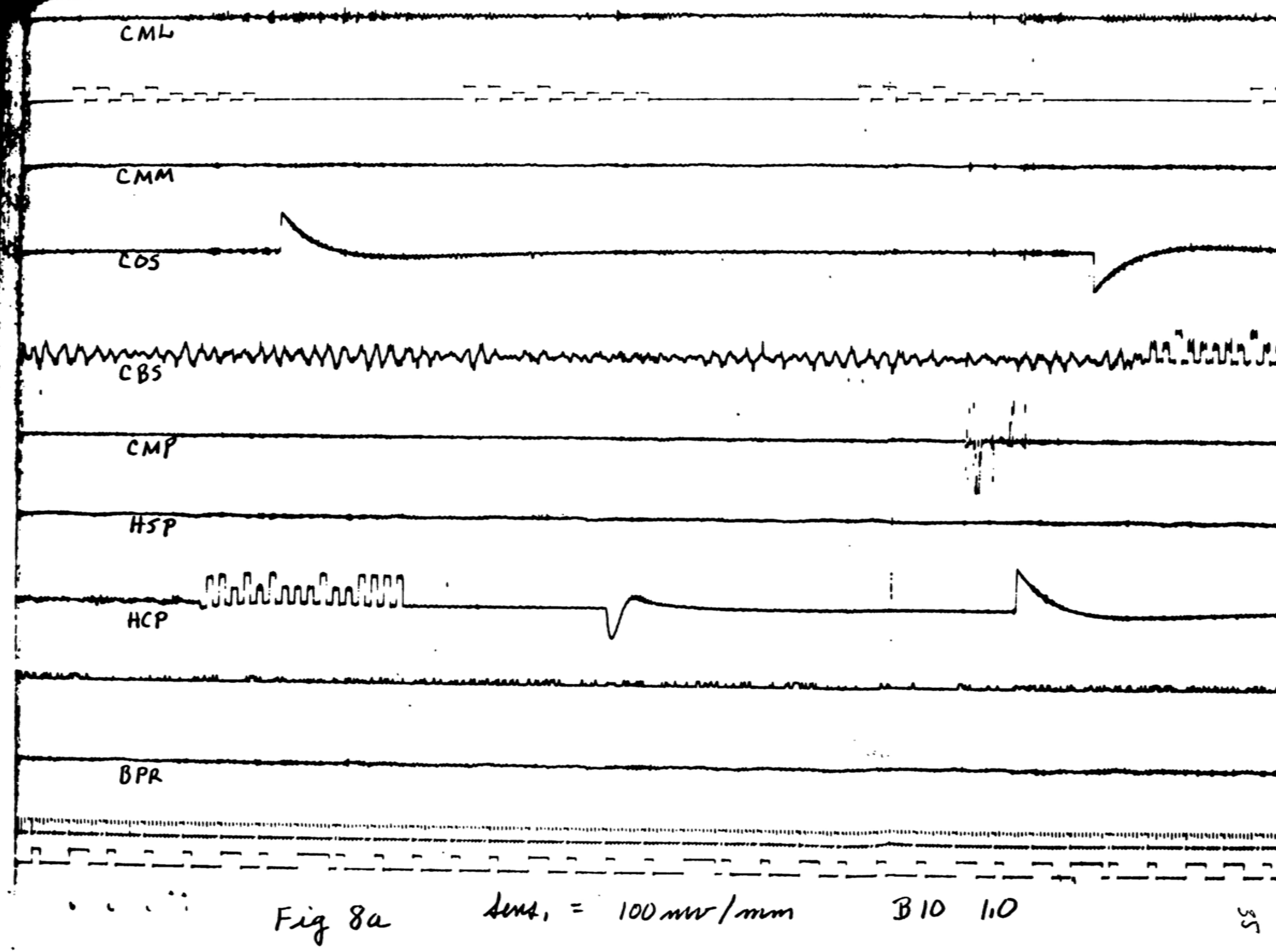




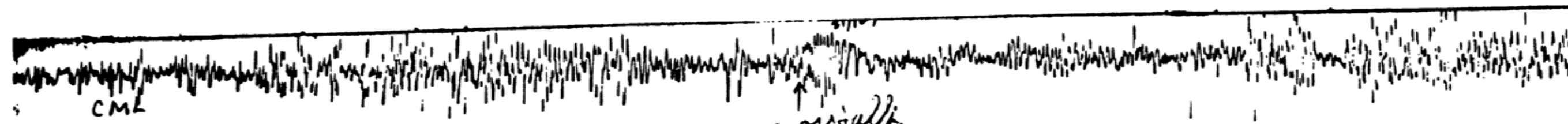

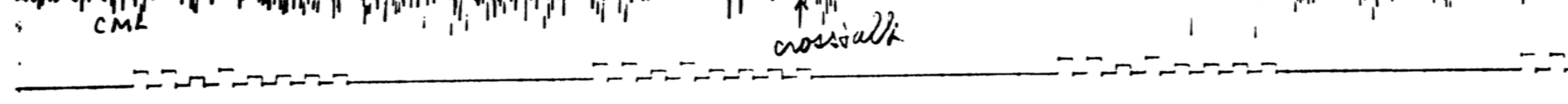

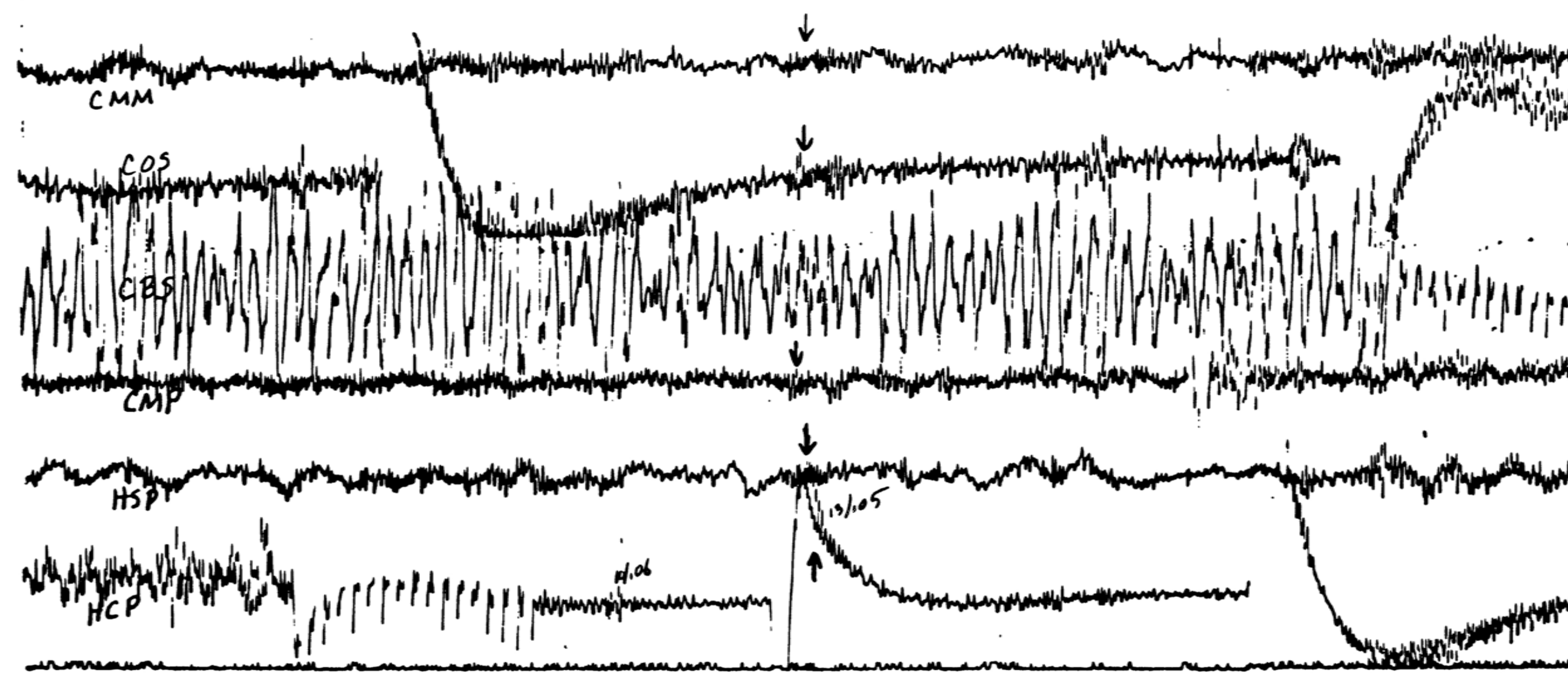

BNR

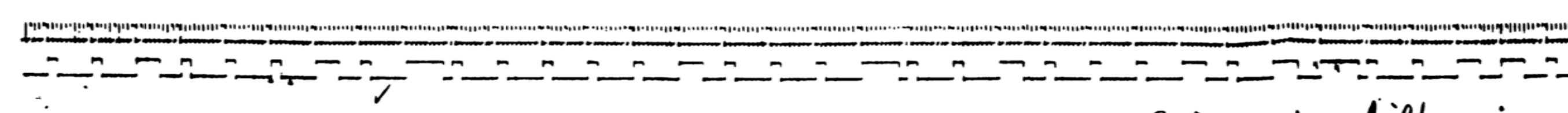

Feg $8 \mathrm{~b} \quad$ Sens. $=10 \mathrm{mw} / \mathrm{mm} \quad B 10 \quad 0.1$ filter in 


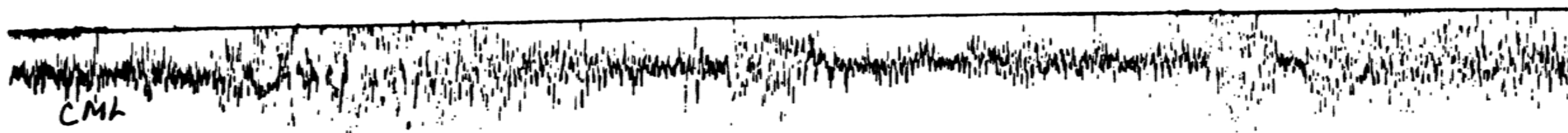
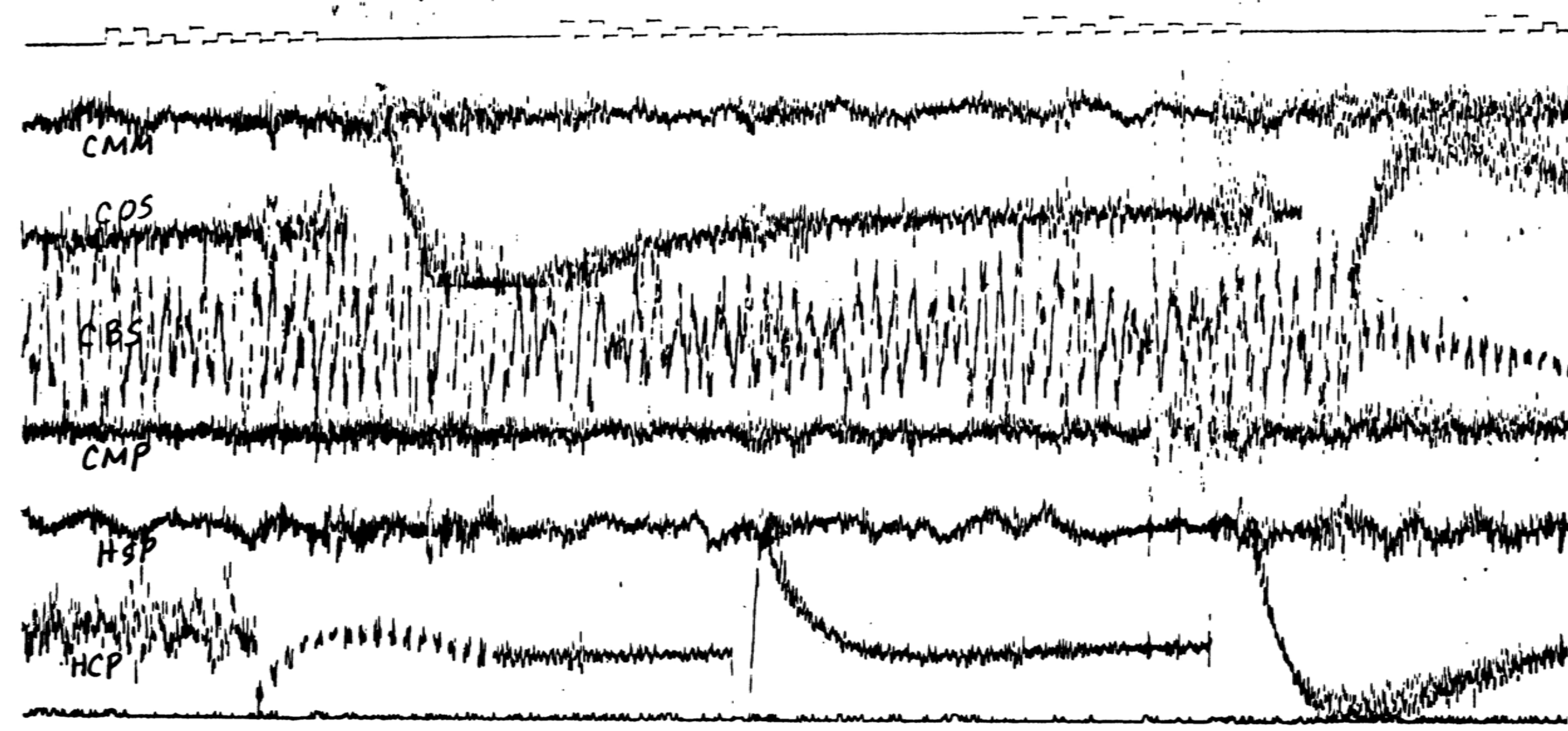

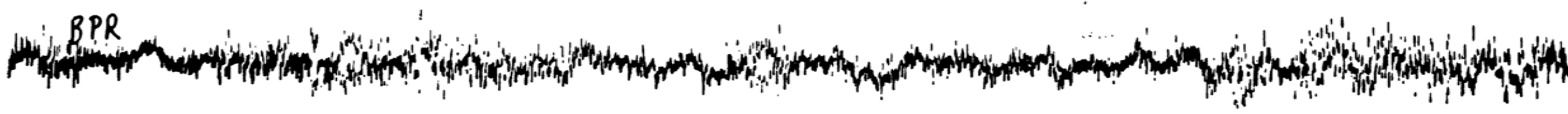

Fig $8 \mathrm{c}$

$\operatorname{Sens}=10 \mathrm{~mm} / \mathrm{mm}$

B10 0.1 felter out w 


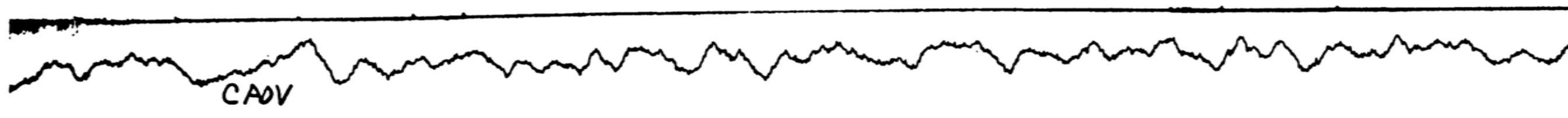

CAOZ

CAOE
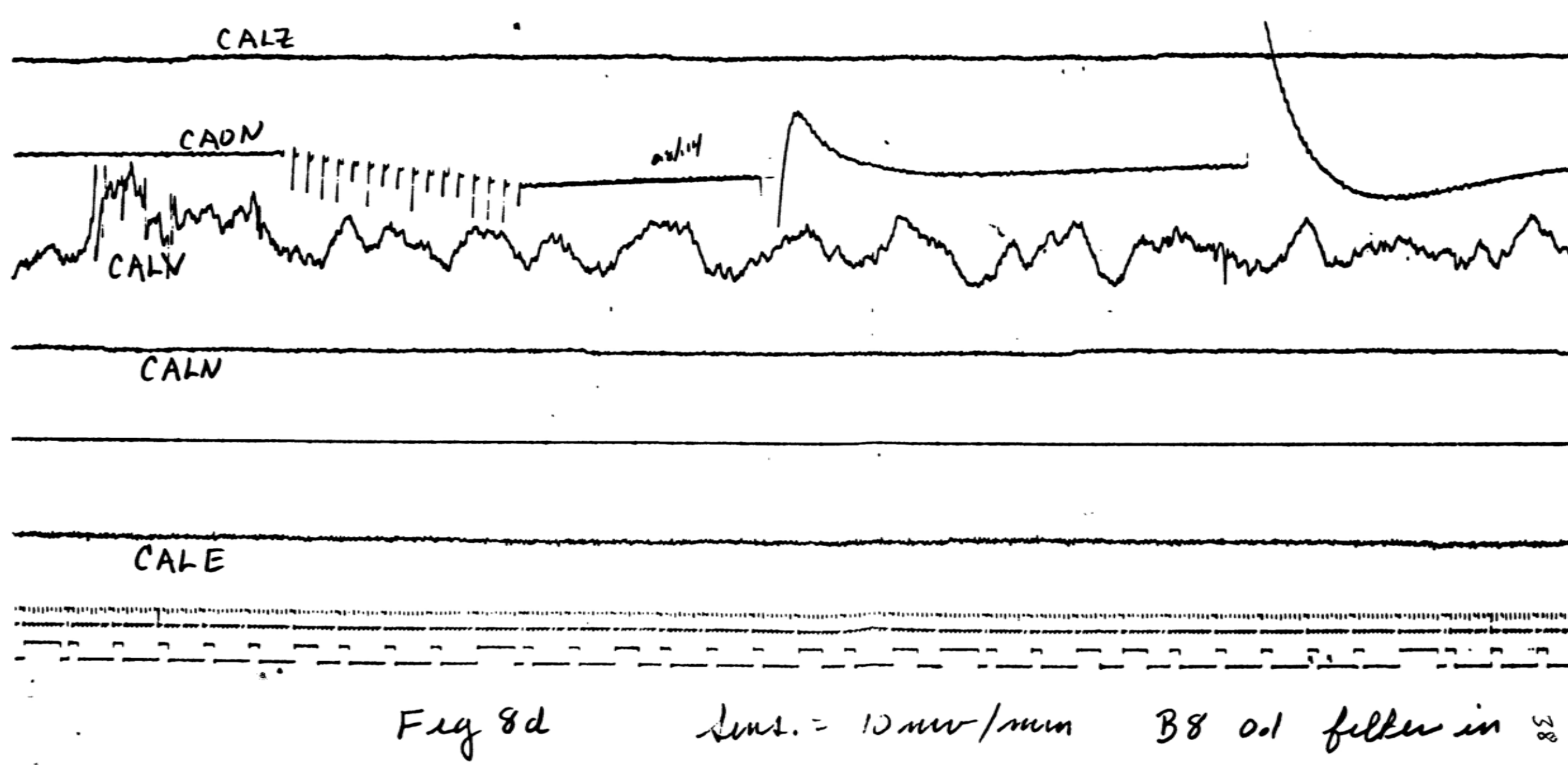


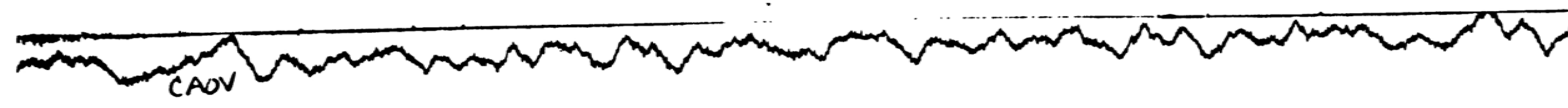

CAOZ

CAOE

CALZ

PAON

CALN

CALE

Feg $8 e$

Sens, $=10 \mathrm{~min} / \mathrm{mm}$

B8 0.1 filtw out 
CAOZ

CAOE

CALZ

CAON

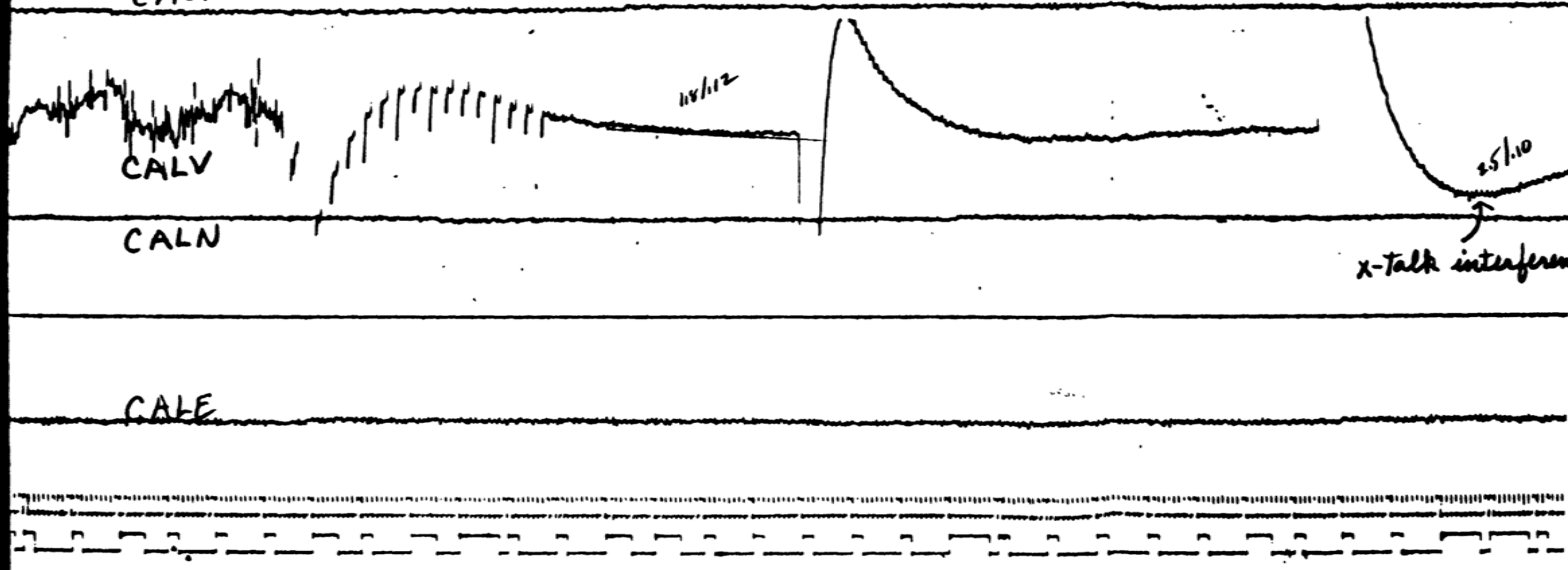

Feg of Sens. $=10 \mathrm{~mm} / \mathrm{mmm} \quad B 80.1$ felter in 


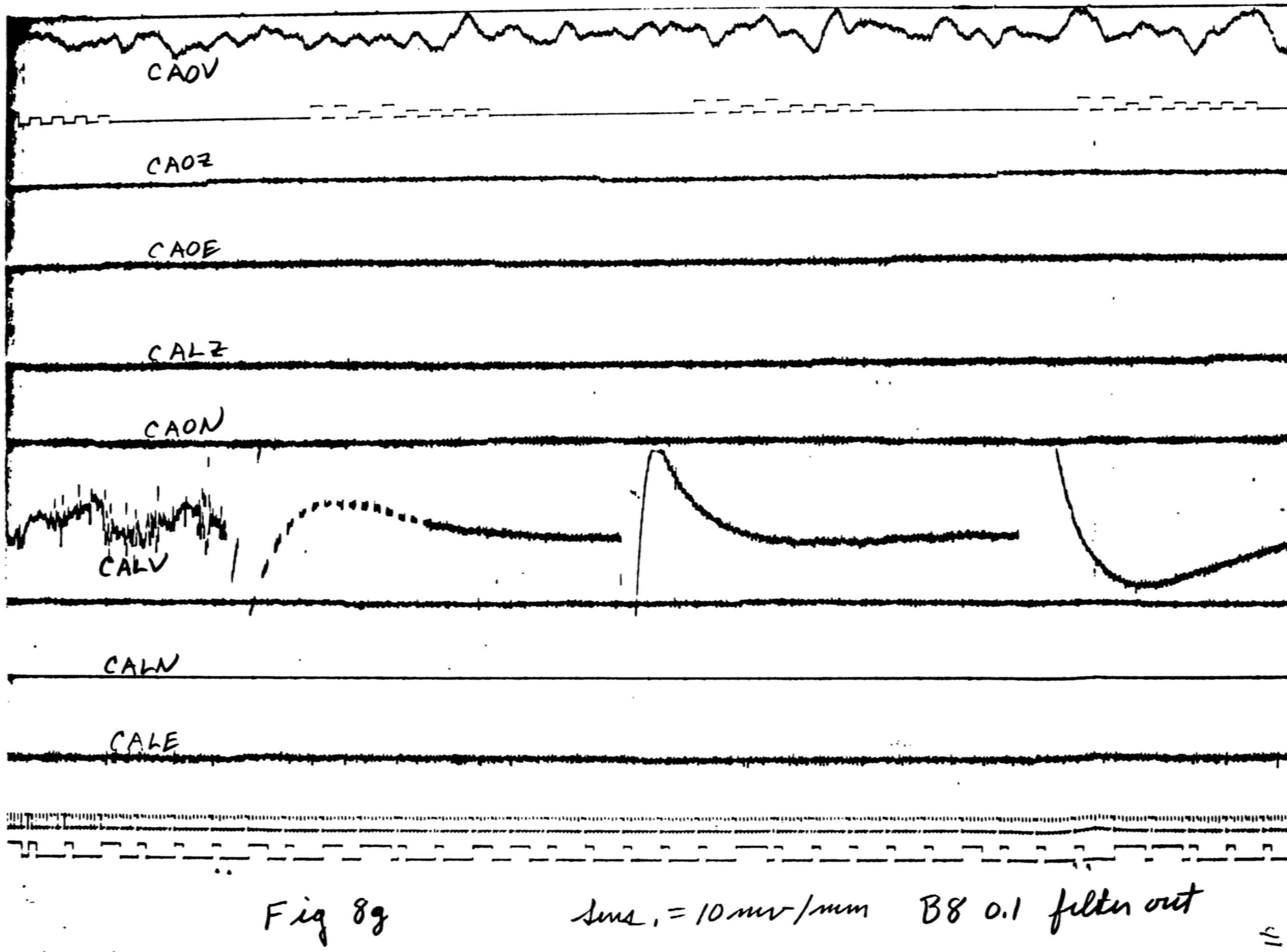


42

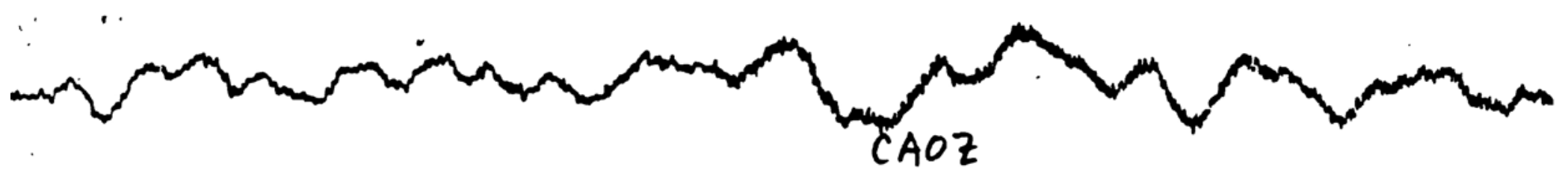

CAOZ

CAOZ

CAOE

CALZ

CAON

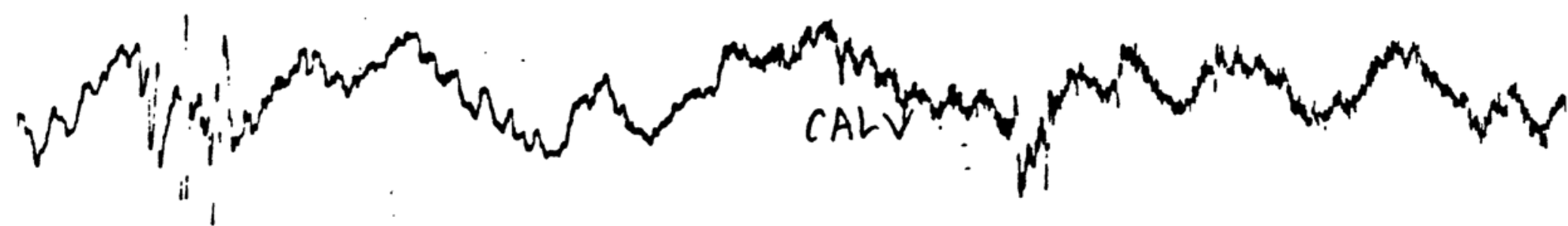

CALN

CALE

off

Fig $8 \mathrm{~h}$

en

fieter

$\operatorname{Sen} \mathrm{A}_{1}=10 \mathrm{mv} / \mathrm{mm} \quad B 8 \quad 0.1$ 


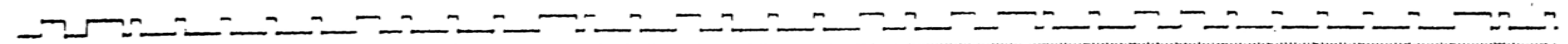

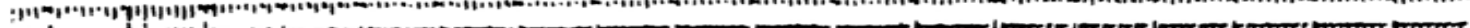

Y BEM

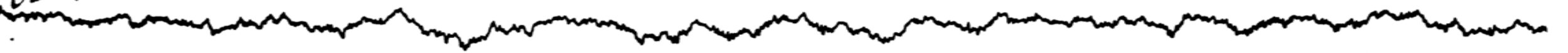

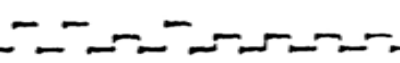

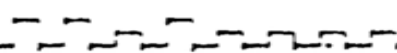

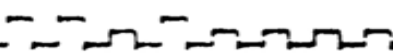

$B C G$ 1)

BMS
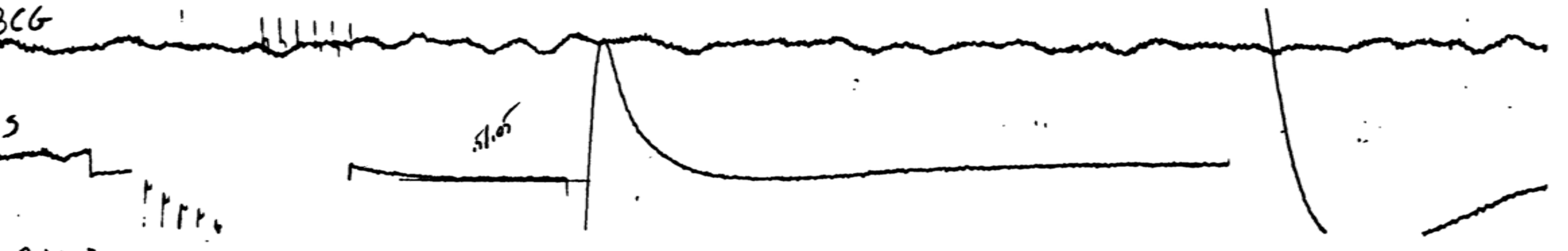

BAVZ

\section{BAVN}

manv BAVE $x_{x-t a l k}^{0.06}$

BEH. 


Big $8 K$




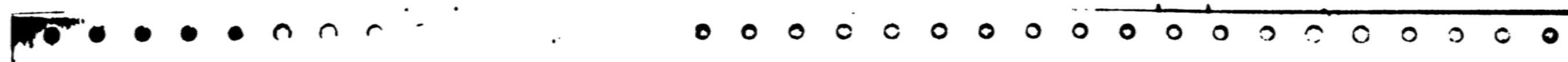

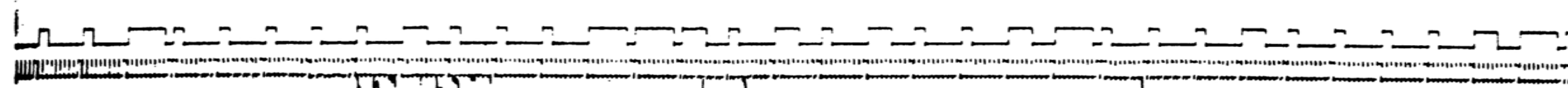

$$
\text { 1MR The }
$$

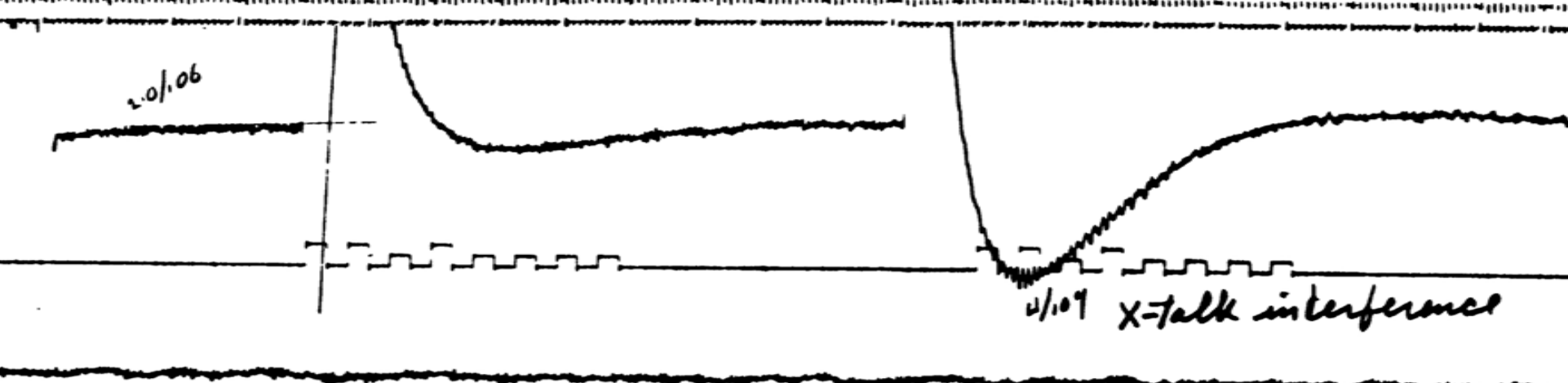

CRA

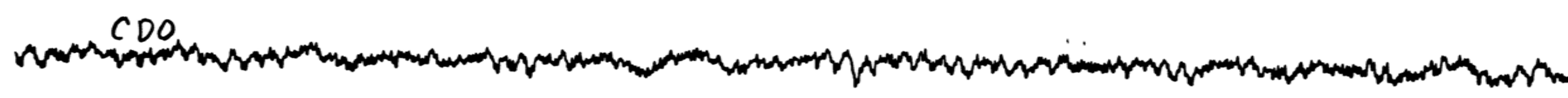

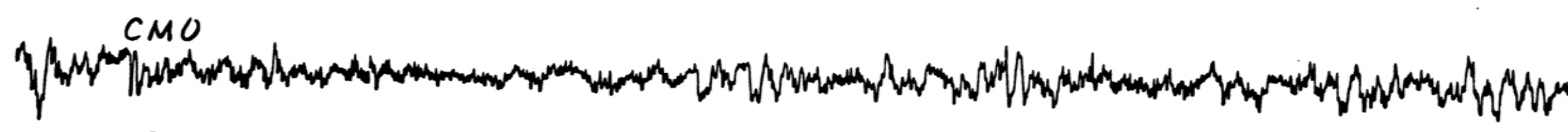
CVA

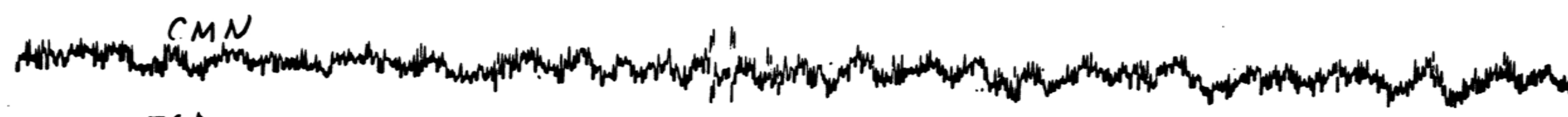

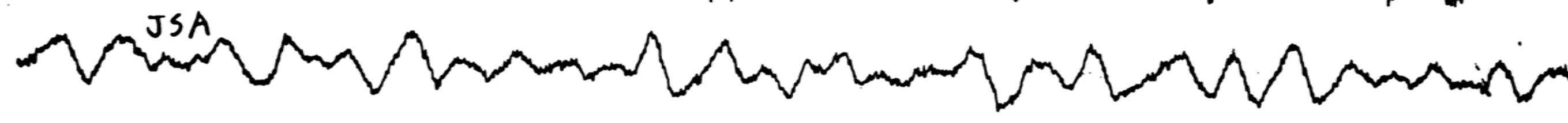

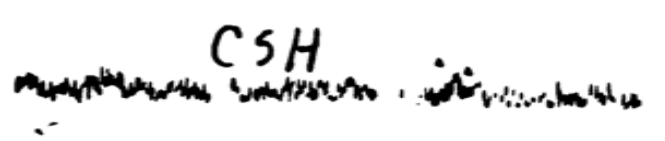

Fig $8 l$

Senc. $=10 \mathrm{men} / \mathrm{men}$ B2 0.1 felter in $\equiv$ 
